\title{
Dynamic fragmentation of Al-W granular rings with different mesostructures
}

\author{
Po-Hsun Chiu ${ }^{1}$, Karl L. Olney ${ }^{2}$, David J. Benson ${ }^{3}$, Chris Braithwaite ${ }^{4}$, Adam Collins ${ }^{4}$, Vitali F.
} Nesterenko $^{1,2}$

${ }^{1}$ Material Science and Engineering program, University of California, San Diego, La Jolla, California 92093, USA

${ }^{2}$ Department of Mechanical and Aerospace Engineering, University of California, San Diego, La Jolla, California 92093, USA

${ }^{3}$ Department of Structural Engineering, University of California, San Diego, La Jolla, California 92093, USA

${ }^{4}$ Fracture and Shock Physics, SMF Group, Department of Physics, Cavendish Laboratory, Cambridge, CB3 OHE, United Kingdom

Abstract: Explosively driven fragmentation mechanisms of Al-W particulate composite rings were investigated. The effect of mesostructure (particulate $\mathrm{Al}$ and $\mathrm{W}$, particulate $\mathrm{Al}$ and $\mathrm{W}$ fibers) and bonding between Al particles (processing via cold isostatic and cold isostatic + hot isostatic pressing) were determined. The kinematics of the expansion process was monitored using Photon Doppler Velocimetry measurements of the velocity of the outer surface of the rings. Numerical simulations of the expansion velocity of rings were in agreement with experimental data. The agglomerated fragments larger than sizes of initial Al particles were observed in experiments. The characteristic size of these agglomerates is most likely determined by the spacing between $\mathrm{W}$ inclusions. The simulations show that dynamically expanded rings had clusters of particulates between shear bands (developing into macrocracks) which expand without significant plastic deformation generating the agglomerated fragments larger than sizes of initial Al particles, as observed in experiments. It was also demonstrated that debris has a measurable fraction of particles with sizes below the original particle sizes. The mesostructure of the fragments demonstrated that $\mathrm{Al}$ particles were heavily deformed within the regions having locally high strain plastic flow, which may result in fragments sizes below initial Al particles diameter. Simulations agree with experiments in that $\mathrm{Al}$ particles between neighboring $\mathrm{W}$ particles/fibers are heavily plastically deformed in comparison with Al particles away from $\mathrm{W}$ inclusions. Simulations also demonstrated that increasing initial porosity increases the plastic straining of $\mathrm{Al}$ particles between $\mathrm{W}$ particles/fibers. Thus initial porosity may cause an increase in temperature of the $\mathrm{Al}$ fragments and cracking their surface oxide layers therefore increasing the chance of subsequent rapid oxidation in air. 


\section{INTRODUCTION}

Metal based reactive materials subjected to high strain, high strain rate plastic deformation and fragmentation are able to provide a significant release of chemical energy by intermetallic reactions ${ }^{1-3}$ and/or oxidation ${ }^{4}$. Shear instability and localization of plastic deformation generate intense heat, fragmentation of particles and initiating reactions within shear bands, which can then propagate into the bulk of the surrounding material ${ }^{5-8}$. Bulk heating of reactive materials due to plastic deformation can also be conducive to their subsequent combustion.

Aluminum ( $\mathrm{Al})$ has very large combustion energy per unit mass $(7422 \mathrm{cal} / \mathrm{g})$ which is approximately five times that of traditional high explosives. The rate of release of this chemical energy strongly depends on the size of the $\mathrm{Al}$ particles. A correlation between the size of $\mathrm{Al}$ particle and their reaction time $t$ (in millisecond) is described by the following equation ${ }^{4}$,

$$
t=0.003 D^{1.99},
$$

where $D$ is the diameter of the Al particles in micrometer $(\mu \mathrm{m})$. Based on Eq. 1 the diameter of $\mathrm{Al}$ particles needs to be on the order of $\sim 20 \mu \mathrm{m}$ in order to have complete reaction within one millisecond.

This size of Al particles, necessary for energy release on this time scale, is very difficult to generate during the fragmentation of homogeneous solid Al samples. A high strain rate fragmentation of solid materials generates the following characteristic fragment sizes $(S)$, due to self-organization of macrocracks ${ }^{9}$

$$
S=\left(\frac{24 \Gamma}{\rho \dot{\varepsilon}^{2}}\right)^{\frac{1}{3}}
$$

where $\Gamma$ is the fracture energy (per unit area), $\rho$ is the density, and $\dot{\varepsilon}$ is the strain rate. For example, a solid Al 6061-T6 alloy in a dynamic process with strain rate $\sim 10^{4} \mathrm{~s}^{-1}$ (e.g., explosively driven expansion of Al tubes) would yield fragments with a characteristic size $S \approx 9$ $\mathrm{mm}$. Replacing solid $\mathrm{Al}$ tubes with loosely packed $\mathrm{Al}$ powders promotes consolidation of $\mathrm{Al}$ particles during shock propagation and subsequent plastic deformation with following expansion resulting in fragments with a typical diameter much larger than $20 \mu \mathrm{m}^{10-13}$. Explosive fragmentation of rings made from densified $\mathrm{Al}$ powder demonstrated that the fragment sizes were orders of magnitude larger than initial size of the powder particles ${ }^{14}$. 
Thus there are few orders of magnitude discrepancy between the required size of $\mathrm{Al}$ particles for fast oxidation and characteristic size of debris generated in high-rate dynamic fragmentation of solid and porous tubes/rings caused by contact explosion. To overcome this large difference between the size scales a highly heterogeneous granular material was introduced $^{15-17}$. This material combines two components ( $\mathrm{Al}$ and $\left.\mathrm{W}\right)$ with very different properties in order to facilitate in situ generation of small scale Al fragments. The high heterogeneity of this material, mostly due to the difference in component densities $\left(19.25 \mathrm{~g} / \mathrm{cm}^{3}\right.$ for $\mathrm{W}$ and $2.73 \mathrm{~g} / \mathrm{cm}^{3}$ for $\mathrm{Al}$ ) facilitates the pulverization of $\mathrm{Al}$ matrix with fragment sizes determined by the material mesostructure and not by self-organization of macrocracks ${ }^{18,19}$.

In this paper, Al-W particulate porous composite rings with different mesostructures were manufactured via cold isostatic and cold isostatic plus hot isostatic pressing. Their dynamic fragmentation was investigated using a relatively soft explosive driver (Primasheet 1000) to gain an insight into the effect of initial mesostructural properties on the fragment size of pulverized $\mathrm{Al}$ matrix. Explosively driven dynamic expansion of these rings was monitored using Photon Doppler Velocimetry (PDV) measurements of the velocity of their outside surface. The experimental setup allowed the soft recovery of a significant portion of the debris. It is important to emphasize that explosive fragmentation of $\mathrm{Al}-\mathrm{W}$ rings in our paper was conducted under the same conditions of dynamic loading as fragmentation of rings made from densified $\mathrm{Al}$ powder ${ }^{14}$ thus elucidating the dramatic influence of their mesostructure on the fragment sizes (about few millimeters in Ref. 14 while the main part of debris in our paper had sizes in the range 1-100 $\mu \mathrm{m})$.

The following variations of initial mesostructural properties of Al-W particulate porous composite rings were investigated: size of $\mathrm{Al}$ particles, morphology of $\mathrm{W}$ component (particles or fibers), and the degree of initial bonding between $\mathrm{Al}$ particles. Numerical simulations were used to characterize the mechanisms of fragmentation during explosively driven expansion and subsequent fragmentation. The experimental results and the numerical simulations demonstrate that the fragmentation of these highly heterogeneous Al-W particulate materials can result in a characteristic scale of debris unattainable by dynamic fragmentation of homogeneous solid or porous materials. 


\section{EXPERIMENTS}

\section{A. Sample preparation}

To investigate the influence of mesostructure (particle size and shapes, and bonding between particles) on the fracture pattern of densified granular materials, a variety of high density Al-W granular/porous composites with different mesostructures were prepared using elemental powders with different particle sizes of $\mathrm{Al}$ and $\mathrm{W}$ morphologies (fibers and powder).

Two types of elemental Al powders were used, a coarse Al powder (Alfa Aesar, -325 mesh) and a fine Al powder (Alfa Aesar, with nominal particle diameters in the range $4.5-7 \mu \mathrm{m}$ according to the manufacturers). The particle size distributions of both Al powders (analyzed by laser diffraction) are shown in Figure 1.

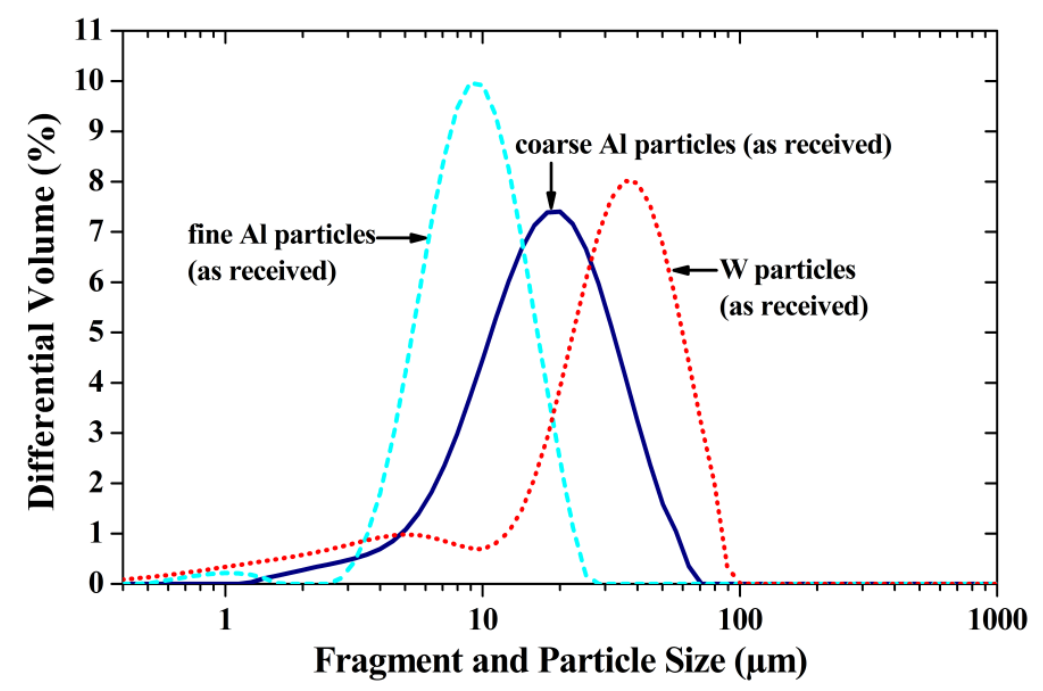

FIG. 1 Size distribution of particles in as received $\mathrm{Al}$ and $\mathrm{W}$ powders from laser diffraction method. The particle sizes corresponding to maxima are $9 \mu \mathrm{m}$ and $20 \mu \mathrm{m}$ for the fine and coarse Al powders, respectively. For $\mathrm{W}$, the corresponding particle size is $36 \mu \mathrm{m}$.

The $\mathrm{W}$ used in the granular mixture consisted of either particles (Alfa Aesar,-325 mesh) or fibers ( $200 \mu \mathrm{m}$ diameter, $4 \mathrm{~mm}$ length). The size distribution of $\mathrm{W}$ particles is also shown in Figure 1. The morphology of as received $\mathrm{Al}$ and $\mathrm{W}$ powders are examined using Scanning Electron Microscopy (SEM) and shown in Figure 2. 

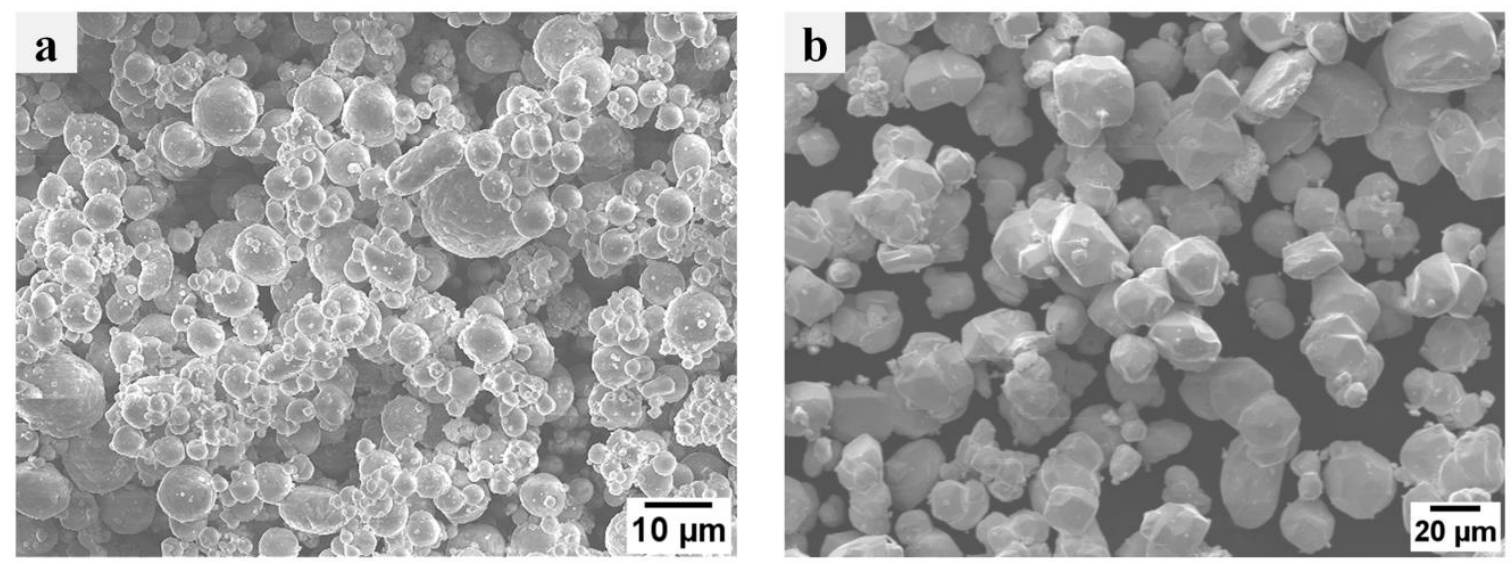

FIG. 2 Particles in as received fine $\mathrm{Al}$ (a) and $\mathrm{W}$ (b) powders. The $\mathrm{Al}$ particles have a more rounded shape compared to the polyhedrons $\mathrm{W}$ particles.

The volume ratio of $\mathrm{Al}$ to $\mathrm{W}$ in all samples was approximately $70 \%$ to $30 \%$, corresponding to the theoretical density of $7.7 \mathrm{~g} / \mathrm{cm}^{3}$ for a solid sample. Different samples porosities and levels of bonding between Al particles were achieved with two pressure assisted techniques (cold isostatic pressing (CIPing) and CIPing followed by a hot isostatic pressing (HIPing)). The latter processing at $450^{\circ} \mathrm{C}$ and $100 \mathrm{MPa}$ for 20 minutes not only increased the density of compacts but also facilitated the partial bonding between Al particles. Sizes of Al particles and $\mathrm{W}$ particles/fibers in investigated rings manufactured by CIPing and CIPing+HIPing are shown in Table I.

TABLE I. Processing methods and sizes of components in the Al-W rings

\begin{tabular}{|c|c|c|c|}
\hline Sample & Processing & Size of Al particles & Sizes of W particles/fibers \\
\hline $1 \mathrm{a}$ & CIPed & $\sim 4.5-7 \mu \mathrm{m}$ & Powder, -325 mesh $(<44 \mu \mathrm{m})$ \\
\hline $1 b$ & CIPed & $\sim 4.5-7 \mu \mathrm{m}$ & Powder, -325 mesh $(<44 \mu \mathrm{m})$ \\
\hline $1 \mathrm{c}$ & CIPed & $\sim 4.5-7 \mu \mathrm{m}$ & Powder, -325 mesh $(<44 \mu \mathrm{m})$ \\
\hline $2 \mathrm{a}$ & CIPed & $-325 \operatorname{mesh}(<44 \mu \mathrm{m})$ & Fiber, Ø $200 \mu \mathrm{m}$, length $4 \mathrm{~mm}$ \\
\hline $2 b$ & CIPed & $-325 \operatorname{mesh}(<44 \mu \mathrm{m})$ & Fiber, Ø $200 \mu \mathrm{m}$, length $4 \mathrm{~mm}$ \\
\hline $3 \mathrm{a}$ & CIPed+HIPed & -325 mesh $(<44 \mu \mathrm{m})$ & Fiber, Ø $200 \mu \mathrm{m}$, length $4 \mathrm{~mm}$ \\
\hline $3 b$ & CIPed+HIPed & $-325 \operatorname{mesh}(<44 \mu \mathrm{m})$ & Fiber, Ø $200 \mu \mathrm{m}$, length $4 \mathrm{~mm}$ \\
\hline $3 \mathrm{c}$ & CIPed+HIPed & -325 mesh $(<44 \mu \mathrm{m})$ & Fiber, Ø $200 \mu \mathrm{m}$, length $4 \mathrm{~mm}$ \\
\hline 4 & CIPed & $\sim 4.5-7 \mu \mathrm{m}$ & Fiber, Ø $200 \mu \mathrm{m}$, length $4 \mathrm{~mm}$ \\
\hline 5 & CIPed+HIPed & $\sim 4.5-7 \mu \mathrm{m}$ & Fiber, Ø $200 \mu \mathrm{m}$, length $4 \mathrm{~mm}$ \\
\hline
\end{tabular}


Mixtures of the $\mathrm{Al}$ and $\mathrm{W}$ components were first ball-milled to prevent the agglomeration of particles using SPEX 800 for 10 minutes with a 1:5 mass ratio of 4 ceramic balls to powder. The mixture was then placed in a cylindrical stainless steel mandrel encapsulated in a rubber jacket ensuring axial loading during pressurization in the CIPing process. All samples were CIPed at $345 \mathrm{MPa}$ under room temperature for $10 \mathrm{~min}$. Cold isostatic pressing of powders does not result in bonding between particles. The initial macrostructural properties of rings are presented in Table II.

Three smaller rings (Sample 1a, 1b and 1c) with $4 \mathrm{~mm}$ height, $19 \mathrm{~mm}$ outer diameter (O.D.) and $13 \mathrm{~mm}$ inner diameter (I.D.) were made from the mixture of fine $\mathrm{Al}$ and $\mathrm{W}$ powders (CIPed only). Samples 2 to 5 represent larger rings with $30 \mathrm{~mm}$ O.D., $22 \mathrm{~mm}$ I.D and $4 \mathrm{~mm}$ height. For comparison, solid stainless steel (SS) 304 rings of size comparable to Sample 1 were tested. Similar processing methodologies were employed for cylindrical samples prepared for quasistatic and dynamic loading using an Instron DYNATUP 9250HV drop weight device as well as for other tests ${ }^{16,17}$.

TABLE II. Initial macrostructural properties of rings after processing.

\begin{tabular}{ccccccc}
\hline \hline Sample & Length $(\mathrm{mm})$ & O.D. $(\mathrm{mm})$ & I.D. $(\mathrm{mm})$ & Weight $(\mathrm{g})$ & Density $\left(\mathrm{g} / \mathrm{cm}^{3}\right)$ & Porosity $(\%)$ \\
\hline $1 \mathrm{a}$ & 4.57 & 19.15 & 12.91 & 5.03 & 7.00 & 10.2 \\
$\mathrm{1b}$ & 4.45 & 19.18 & 12.93 & 4.88 & 6.96 & 10.8 \\
$1 \mathrm{c}$ & 4.60 & 19.23 & 12.90 & 5.24 & 7.14 & 8.5 \\
2a & 4.16 & 30.10 & 21.73 & 8.94 & 6.64 & 14.9 \\
$\mathrm{2b}$ & 4.08 & 30.07 & 21.77 & 8.93 & 6.61 & 15.2 \\
$3 \mathrm{a}$ & 4.09 & 29.61 & 21.37 & 8.99 & 7.05 & 9.6 \\
$3 \mathrm{~b}$ & 4.03 & 29.64 & 21.33 & 8.96 & 7.11 & 8.8 \\
$3 \mathrm{c}$ & 4.11 & 29.71 & 21.42 & 9.01 & 6.98 & 10.4 \\
4 & 4.03 & 30.01 & 21.79 & 8.89 & 6.77 & 13.2 \\
5 & 4.05 & 29.71 & 21.39 & 9.31 & 7.16 & 8.2 \\
\hline \hline
\end{tabular}

The procedure produced rings with a good tolerance. The samples after CIPing had approximately $9-15 \%$ porosity while the samples after CIPing+HIPing had approximately 8-10\% porosity. After processing using CIPing and CIPing+HIPing, the tube/ring shaped samples did not require any additional machining prior to the dynamic explosively driven fragmentation tests. 
The microstructure of the densified and polished samples of rings after processing is shown in Figure 3. It can be seen that Al particles are densely packed and deformed into isotropic polyhydrons. The amount of pore space is significantly reduced after the combined CIPing+HIPing process in both coarse and fine Al particles.
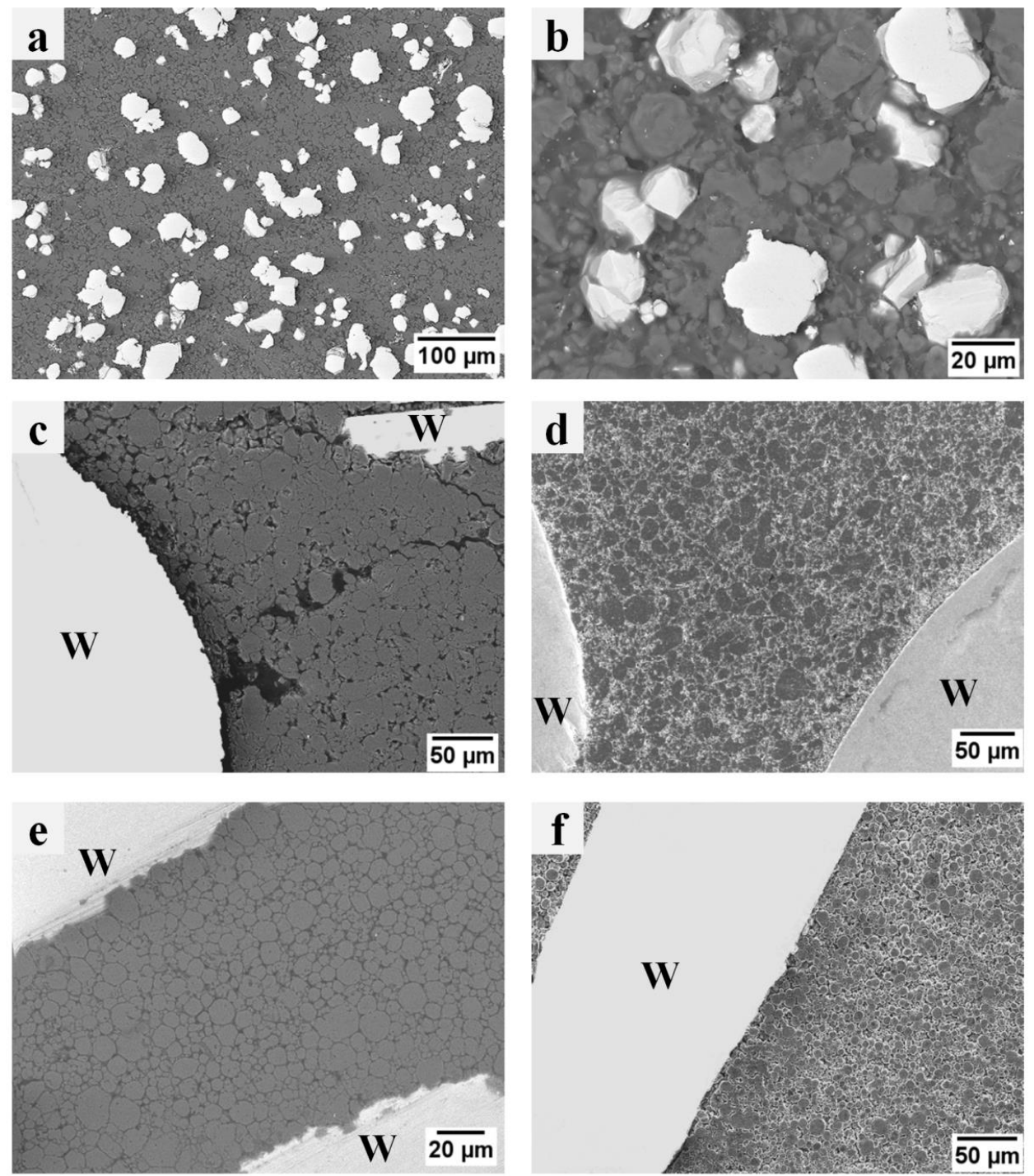

FIG. 3 SEM images of the rings made from fine $\mathrm{Al}$ and coarse $\mathrm{W}$ powders/fibers after corresponding pressure assisted processing: (a) and (b) different magnifications of the CIPed Sample 1a composed of fine Al powder (dark gray particles) and W powder (white particles); (c) CIPed Sample 2a of coarse Al powder and W fibers; (d) CIPed+HIPed Sample 3a of coarse Al powder and W fibers (e) CIPed Sample 4 of fine Al powder and W fibers; (f) CIPed+HIPed Sample 5 of fine Al powder and W fibers.

\section{B. Explosively driven fragmentation experiments}

The explosively driven dynamic expansion of the ring shaped samples was investigated in the experimental setup presented in Refs. 14, 18, and 19. Dynamic pressure was applied to the 
inner surface of ring samples through a copper tube placed inside the sample which is in turn driven by explosive detonation products. The weight of the explosive detonation products for each sample is presented in Table III. Low density, low strength substances Paraffin wax ${ }^{18}$ (used for Samples 1) or polyethylene glycol ${ }^{19}$ (PEG, for Samples 2-5) were used for the soft capture of fragments. The amount of materials recovered after the explosively driven fragmentation tests is also presented in Table III.

TABLE III. The weight of explosive detonation products and amount of recovered debris after the fragmentation test.

\begin{tabular}{cccc}
\hline \hline Sample & charge weight $(\mathrm{g})$ & ratio (charge/samples weight) & $\%$ mass recovered \\
\hline $1 \mathrm{a}$ & 0.86 & 0.19 & 23 \\
$1 \mathrm{~b}$ & 0.91 & 0.17 & 37 \\
$1 \mathrm{c}$ & 0.98 & 0.19 & 46 \\
$2 \mathrm{a}$ & 3.48 & 0.39 & 67 \\
$2 \mathrm{~b}$ & 3.45 & 0.40 & 89 \\
$3 \mathrm{a}$ & 3.62 & 0.40 & 56 \\
$3 \mathrm{~b}$ & 3.62 & 0.39 & 82 \\
$3 \mathrm{c}$ & 3.65 & 0.39 & 73 \\
4 & 3.57 & 0.40 & 84 \\
5 & 3.63 & 0.40 & 62 \\
\hline \hline
\end{tabular}

Examples of fragments recovered after comparable experiments with stainless steel rings and the CIPed samples with fine Al and W powders are shown in Figure 4(a) and Figure 4(c), respectively and Figure 4(b) shows an initial Al-W ring before testing. The comparison between Figure 4(a) and (c) clearly demonstrates that the mesostructure of $\mathrm{Al} / \mathrm{W}$ sample played a major role in the generation of multiple small scale fragments with sizes in the range $10-100 \mu \mathrm{m}$ that are significantly smaller than the fragment size of SS rings (5-10 millimeters). The SS fragment sizes are of the order of magnitude predicted by the Grady-Kipp equation (Eq. 2). 

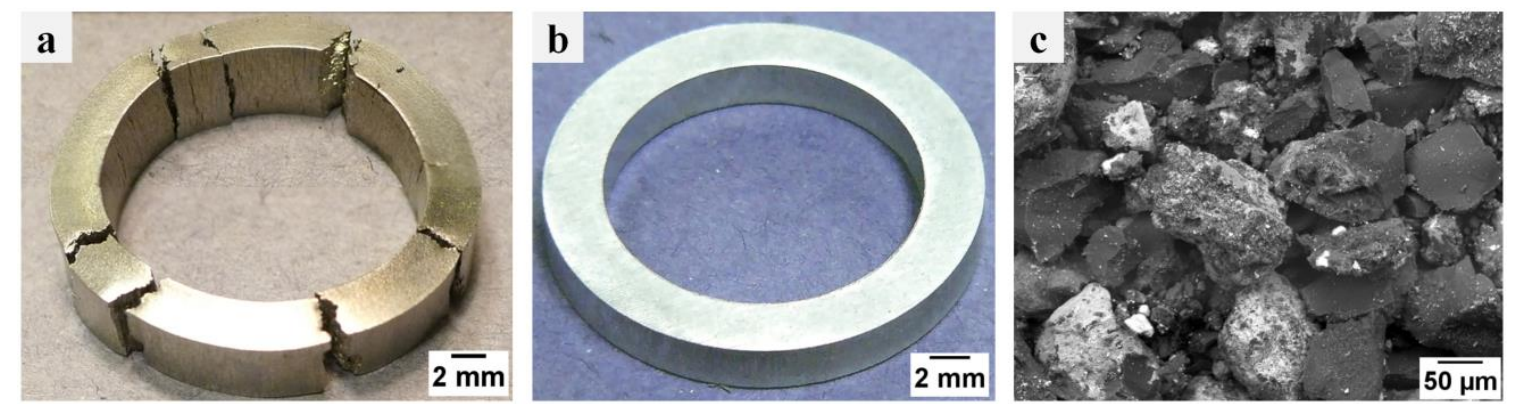

FIG. 4 Fragments recovered after comparable explosively driven fragmentation of solid and granular rings with similar density and sizes, but with different strength and mesostructures: (a) fragments from solid steel ring with sizes similar to Sample 1; (b) an example of initial Al-W ring and (c) fragments from Al-W Sample 1a fabricated from $\mathrm{Al}$ and $\mathrm{W}$ powders.

Examples of $\mathrm{W}$ fibers before and after fragmentation tests are shown in Figure 5. W fibers in Figure 5(a) were retrieved from a CIPed coarse Al/W fibers sample after Al matrix was removed by acid etching and $\mathrm{W}$ fibers in Figure 5(b) were recovered from debris after fragmentation test of Sample 2a. W fibers after fragmentation tests do not show significant change of their shape or fragmentation. Thus, their plastic deformation did not absorb a significant part of the available energy of explosive, meaning that this energy was available for the plastic deformation and fragmentation of light, low strength Al particles. The Al particles are squeezed between the heavier, higher strength W fibers both during shock loading and in the later stages of sample expansion. The preferential deformation and fragmentation of light and small low strength particles in mixture with heavy, large, high strength particles under shock loading was reported in Refs. 6, 20, and 21. The influence of the elongated shape of W fibers on the fragmentation process of Al matrix could be significant, with fibers potentially having a greater deforming effect than equiaxed $\mathrm{W}$ particles.
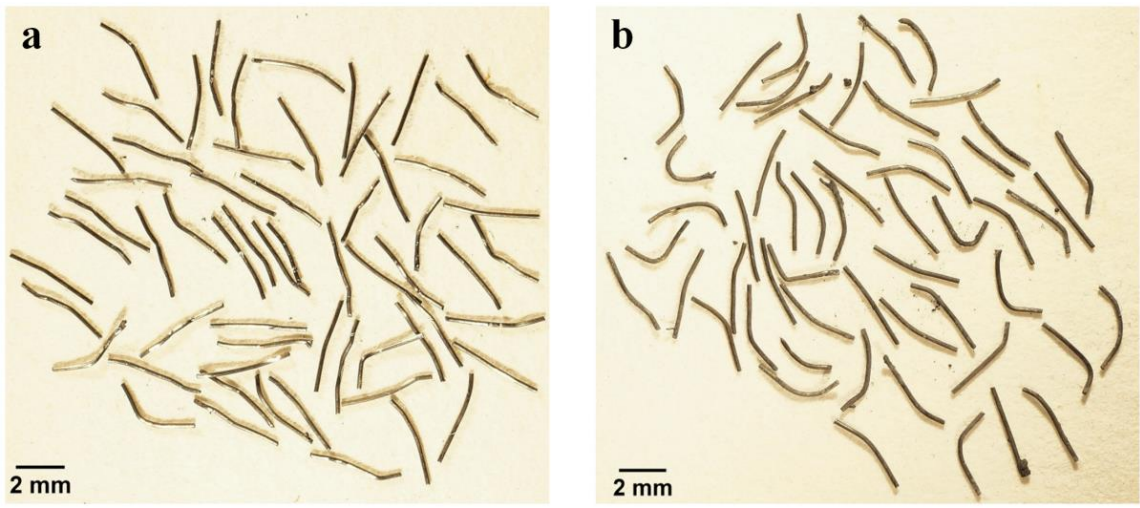

FIG 5. Examples of W fibers collected from the samples after (a) CIPing and after (b) fragmentation tests of the Sample 2a. 
Photon Doppler Velocimetry (PDV or Het-V), with a nominal laser power output of $140 \mathrm{~mA}$ was used to capture time-resolved velocity of a portion of the expanding Al-W or steel rings. The PDV system was built with the assistance of AWE Aldermaston. The PDV data were sampled at $20 \mathrm{GHz}$ and processed with a Hamming window over 4,096 points. The PDV records after post processing are presented in Figure 6.
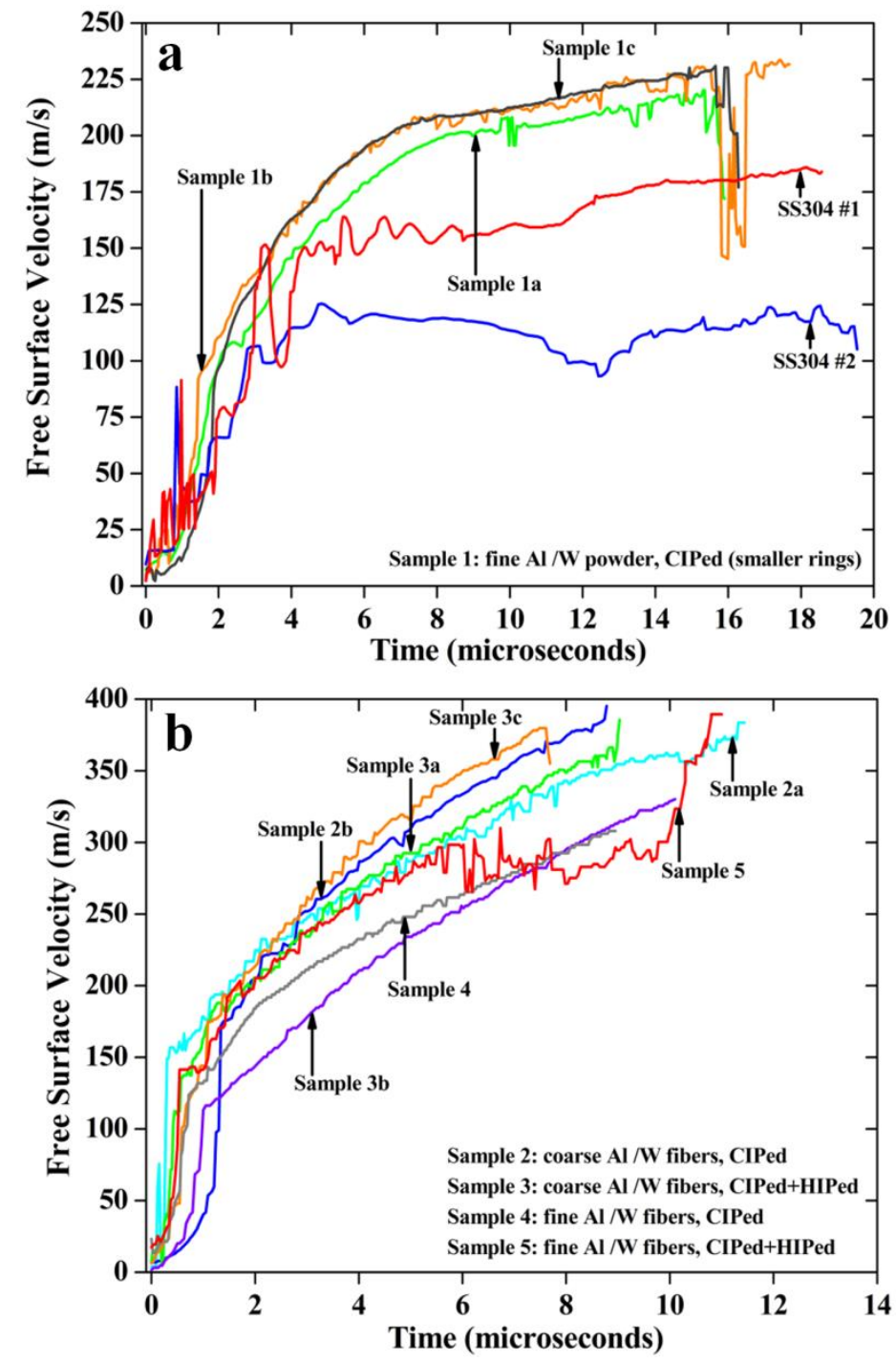

FIG. 6 Velocity profiles of the outside surface of ring samples with different initial mesostructures: (a) data for the small CIPed ring samples made from $\mathrm{Al}$ and $\mathrm{W}$ powders, and for the stainless steel ring of the same size; (b) data for the larger CIPed and CIPed+HIPed rings made from Al powder and W fibers.

The small rings made from CIPed fine $\mathrm{Al}$ and $\mathrm{W}$ powders (Samples 1a-1c), demonstrate smooth and repeatable profiles of the expansion velocity (Figure 6(a)), unlike large difference in velocity profiles for different stainless steel samples (SS304 \#1 and \#2). This result is interesting 
because the recorded expansion velocities correspond to the expansion of low strength dense clusters of particulate materials (the CIPing did not introduce any bonding between $\mathrm{Al}$ particles or between $\mathrm{Al}$ and $\mathrm{W}$ particles). Al-W samples experienced uniformly distributed fragmentation pattern resulting in the uniform distribution of circumferential expansion velocity and in a small size of debris (Figure 4(c)). This can be explained by low strength of these samples causing bulk distributed fragmentation, which prevents the generation of few macrocracks on early stages of expansion, as was the case for stainless steel samples (Figure 4(a)).

Two SS rings (with sizes similar to Sample 1) tested under similar conditions of explosive loading demonstrated lower expansion velocities in the range $120-180 \mathrm{~m} / \mathrm{s}$ with a larger variation in recorded data between two tests. The larger variation of expansion velocities can be attributed to the different fragmentation pattern, e.g. breaking into few relatively lager segments with various mass (Figure 4 (a)) accelerated to different velocities of outside surface by detonation products

The maximum detected velocity for Samples 1a-1c was $\sim 230 \mathrm{~m} / \mathrm{s}$. An estimated outside radius of the sample at this moment is $11.6 \mathrm{~mm}$, which corresponds to the strain rate about $2 \cdot 10^{4}$ $\mathrm{s}^{-1}$. A similarly estimated outside radius of the larger Samples 2-5 (Figure 6(b)) at the moment corresponding to their maximum velocity $(\sim 350 \mathrm{~m} / \mathrm{s})$ is $17 \mathrm{~mm}$. This corresponds to the strain rate about $2 \cdot 10^{4} \mathrm{~s}^{-1}$, which is similar to the strain rate of smaller samples at corresponding moments of expansion. The larger maximum velocity of expansion of the Samples 2-5 is due to larger ratio of explosive to the mass of the rings (Table III).

A comparison of the samples for coarse $\mathrm{Al}$ powder and $\mathrm{W}$ fibers (Samples 2 versus Samples 3) allows the effect of the HIPing process to be investigated. The CIPed only samples show a relatively small data spread (Figure 6(b)), suggesting a bulk distributed fragmentation pattern. The samples which had been HIPed showed a greater spread, indicating that the partial bonding between Al particles introduced by HIPing may conducive to the generation of a few macrocracks. The behavior of CIPed+HIPed samples therefore tends towards what one might expect for "standard" fragmentation with larger sizes of debris.

\section{X-ray diffraction analysis of fragment compositions}

The densified particulate materials in the explosively driven fragmentation tests experienced shock wave loading and high strain, high strain rate plastic deformation with 
subsequent fragmentation. These conditions may result in chemical reactions between components $^{22,23}$, in this case between $\mathrm{Al}$ and $\mathrm{W}$. This reaction is not desirable for generation of small scale reactive Al particles.

In order to identify possible reaction products in the fragments, X-ray Powder Diffraction (XRPD) was performed on a Rigaku MiniFlex II system in the Scripps Institution of Oceanography, UCSD and the results are presented in Figure 7.

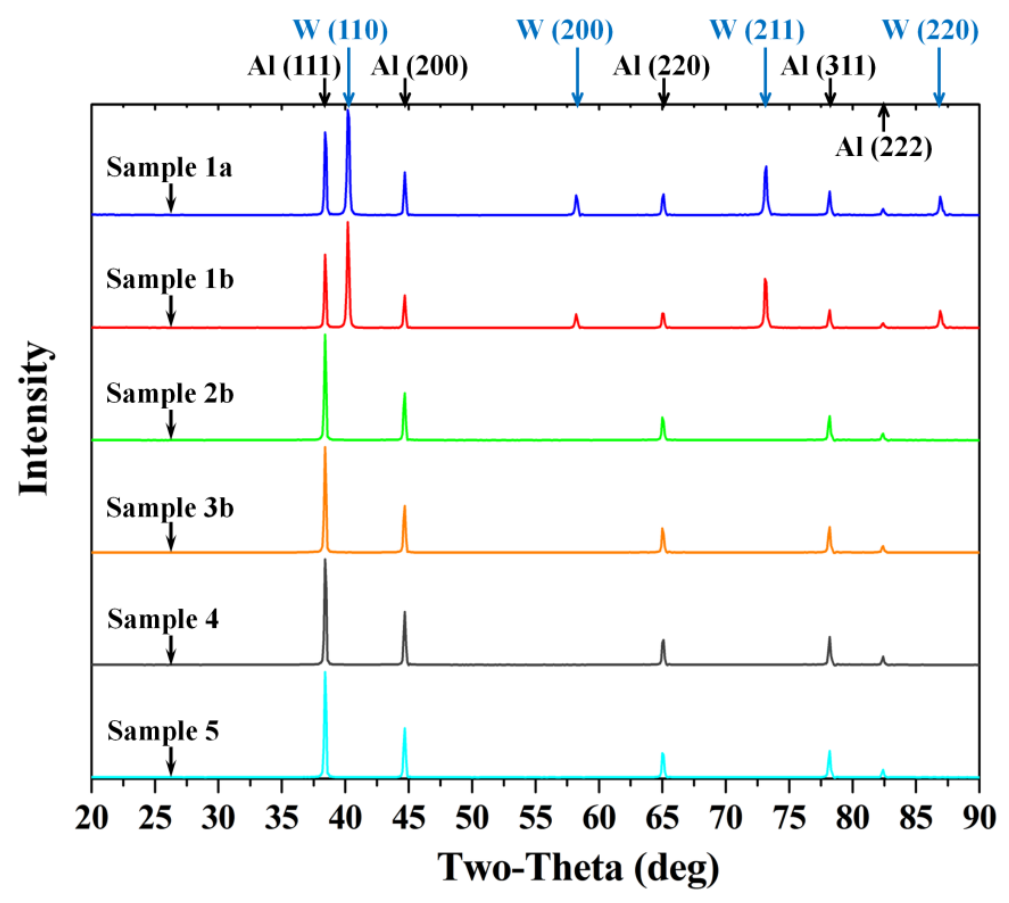

FIG. 7 The XRPD results of recovered fragments from corresponding rings made from Sample 1 (fine Al/coarse W powders, CIPed only), Sample $2 b$ (coarse Al powder/W fibers, CIPed only), Sample 3b (coarse Al powder/W fibers, CIPed+HIPed), Sample 4 (fine Al powder/W fibers, CIPed only) and Sample 5 (fine $\mathrm{Al}$ powder/W fibers, CIPed+HIPed). Diffraction peaks corresponding to pure $\mathrm{Al}$ and $\mathrm{W}$ are shown by vertical arrows at the top of the figure.

It is clear that diffraction peaks corresponding to pure $\mathrm{Al}$ and $\mathrm{W}$ were present in the debris. W lines are not present in fragments from Samples 2b, 3b, 4 and 5 because the W fibers were removed before the XRD analysis. The results shown in Figure 7 demonstrate that Al and $\mathrm{W}$ in the samples did not react during the experiment. For example, a strong peak at $75^{\circ}$ corresponding to $\mathrm{Al}_{4} \mathrm{~W}$ is not present ${ }^{24}$. 


\section{Size distribution of fragments}

The particle size distributions of the recovered fragments were analyzed by laser diffraction using a wet dispersion technique (Hydro S accessory) in a Mastersizer 3000 particle size analyzer. This methodology follows the broad recommendations outlined in ISO13320, the international standard for laser diffraction. The sample was placed in $20 \mathrm{ml}$ of a $1 \%$ solution of Tween 20 and water. Then it was placed in an 80 watt ultrasonic bath for 5 minutes before the laser analysis in order to wet the surfaces and disperse agglomerated fragments. Three batches of material from each sample were analyzed. The distribution of recovered fragments for all samples is presented in Figure 8. The results were repeatable with about $30 \%$ of the fragments having sizes below $100 \mu \mathrm{m}$. 

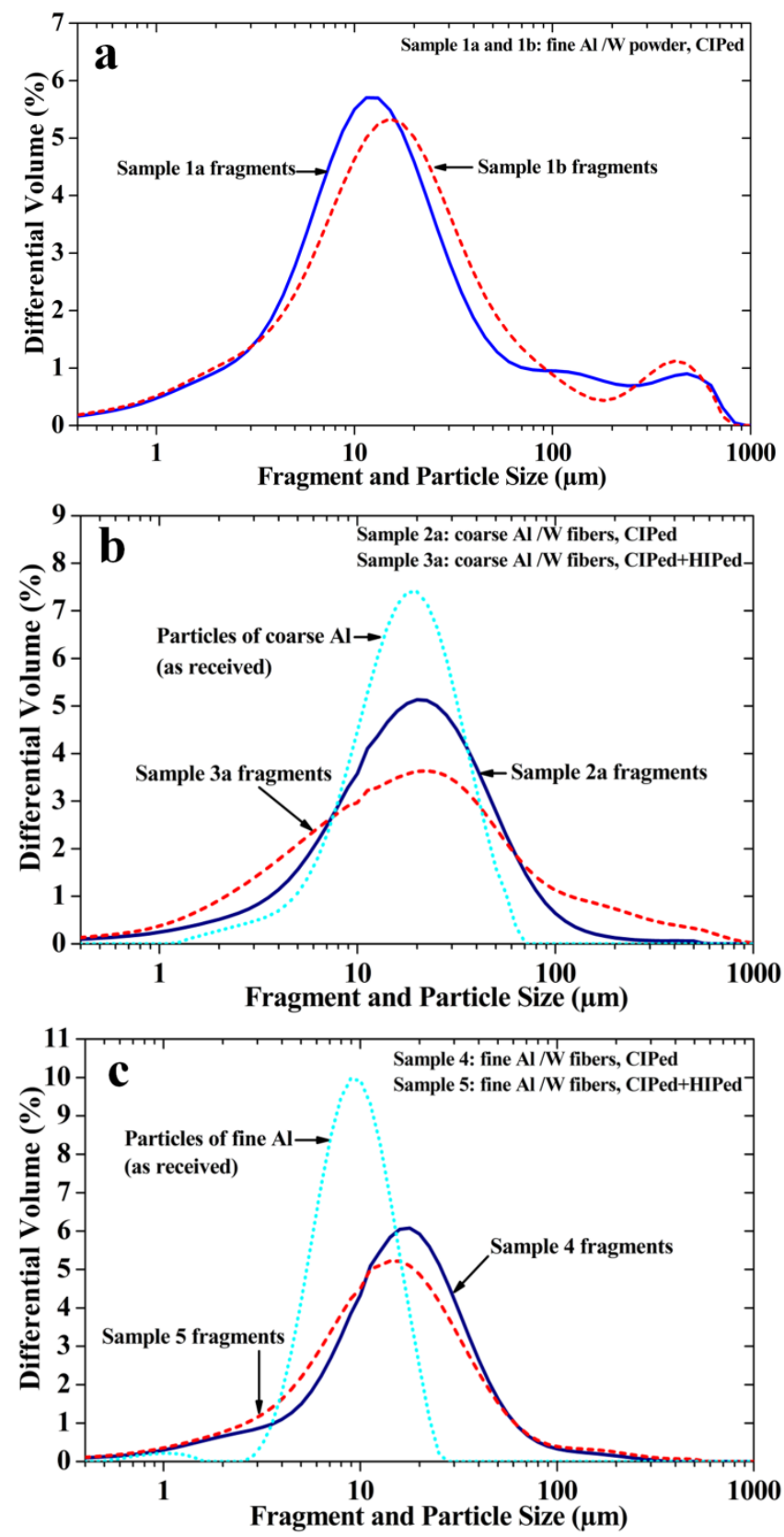

FIG. 8 The size distribution of the recovered fragments after tests of CIPed fine Al/W powder rings (a); from CIPed and CIPed+HIPed coarse Al powder/W fibers (b); and from fine Al powder/W fibers (c). The particle size distribution of as-received Al powder was also shown in (b) and (c).

In all tested samples, the mean fragment size is approximately 10-20 $\mu \mathrm{m}$. This fragment size is independent of the initial Al particle size, initial $\mathrm{W}$ powder/fiber sizes, initial dimensions of the sample, or difference in processing (CIPed vs CIPed+HIPed). This indicates that mean fragment size does not scale with the size of initial Al particles. An appropriate alternative length scale is that of the spacing between the W particles/fibers (it is similar in all samples because of 
the similar volume content of $\mathrm{W}$ ), and it is suggested that this is the most instrumental factor in determining the fragment size distribution.

In CIPed samples with $\mathrm{Al}$ and $\mathrm{W}$ powders (Figure 8(a), there is a secondary, smaller maximum in the fragment size distribution, corresponding to a fragment size of $\sim 200-500 \mu \mathrm{m}$ with $\mathrm{W}$ particles embedded in the Al matrix as seen in the SEM micrographs (see Figure 9 in the next section). This is a feature not seen in the samples with W fibers. We may speculate that in case of $\mathrm{W}$ fibers higher dimensionality and possible different three dimensional modes of motion (compared with equiaxed $\mathrm{W}$ particles) may contribute to more effective fragmentation of CIPed only $\mathrm{Al}$ agglomerates. $\mathrm{W}$ fibers also have a larger mass than $\mathrm{W}$ particles resulting in a more efficient breaking of $\mathrm{Al}$ agglomerates attached to them.

It is interesting that there is noticeable number of $\mathrm{Al}$ fragments with sizes smaller than the initial powder demonstrating that some particles were fractured during the dynamic deformation. Furthermore it is likely that the missing mass from the rings (see Table II) is from the bottom end of the fragment size distribution as this is the most difficult to recover. This means that the fracturing may be even more extensive than the result suggests. The CIPed and CIPed+HIPed rings made of $\mathrm{W}$ fibers and fine $\mathrm{Al}$ particles for example, both have significant number of particles with sizes below $7 \mu \mathrm{m}$ and about $13 \%$ of particles below $4 \mu \mathrm{m}$ for CIPed and about $9 \%$ for CIPed+HIPed sample (Figure 8(c)). In all samples, 3-6\% of the particles have a size less than $2 \mu \mathrm{m}$ compared to $\sim 1 \%$ in the constituent materials.

The fragments size distributions for the samples with $\mathrm{W}$ fibers and coarse Al powders processed using CIPing+HIPing demonstrated a noticeable number of debris with size up to 700 $\mu \mathrm{m}$. These larger sizes of debris are not presented in CIPed+HIPed samples with W fibers and fine Al powders.

Another interesting observation is that the samples with coarse Al particles that were CIPed only have a tighter particle size distribution around the first peak in comparison to the samples that were processed with CIPing and HIPing (Figure 8(b)). The partial bonding between Al particles introduced by HIPing may be responsible for more narrow distribution of fragments in CIPed versus CIPed+HIPed fine Al particles.

We consider that the main stage in the fragmentation process is likely to occur during the stage of initial shock wave loading followed by expansion and dynamic deformation of rings. The possibility of an additional fragmentation upon debris impact on paraffin wax/PEG can't 
truly be ignored. However it does not negatively impact one of the major findings of our research: densified assembles of $\mathrm{Al}$ particles, even without any bonding between them, generated significant portion of fragments having many $\mathrm{Al}$ particles.

Another major result of our paper is the observation of $\mathrm{Al}$ particles with sizes less than their initial sizes. We also consider that these fine particulates were created during initial high strain rate expansion and dynamic deformation of Al particles which were squeezed and fractured between $\mathrm{W}$ inclusions and inside localized shear zones.

The rational supporting this conclusion is the following. Al particles are rather ductile and thus it is reasonable to expect that their impact on low density paraffin wax $\left(0.9 \mathrm{~g} / \mathrm{cm}^{3}\right)$ or PEG $\left(1.1 \mathrm{~g} / \mathrm{cm}^{3}\right)$ with low strength most probably will result in some plastic deformation of $\mathrm{Al}$ particles and not in their fracture into smaller fragments than size of the particles. This is supported by the experimental results related to the impact of individual $\mathrm{Al}$ particles onto a higher density (about $8.5 \mathrm{~g} / \mathrm{cm}^{3}$ ) and relatively hard brass substrate with velocities $400-500 \mathrm{~m} / \mathrm{s}$ during a kinetic spray process ${ }^{25}$. Numerical analysis ${ }^{26}$ of the critical velocity required for onset of ductile fracture of Al particles impact onto a brass substrate resulted in a value about $450 \mathrm{~m} / \mathrm{s}$. In our experiments, the velocities of the expanding rings were in the range $220-400 \mathrm{~m} / \mathrm{s}$ and $\mathrm{Al}$ debris impacted the very soft, low density paraffin wax or PEG substance and not a significantly denser and harder brass substrate. Thus, any significant fragmentation of Al particles impacting paraffin wax or PEG substance is improbable. It is also indirectly supported by the fact that even debris composed of low strength agglomerates of unbonded Al particles were preserved by the paraffin wax/PEG soft capture medium.

\section{E. Mesostructure of fragments}

To investigate the mesostructure of recovered fragments, a portion of the fragments were cold-mounted in epoxy and then polished and etched in $\mathrm{HNO}_{3}-\mathrm{HF}$ (3:1 by volume) for 30 seconds. The fragments were then examined using Scanning Electron Microscopy (SEM).

Two larger sized fragments $(\sim 100 \mu \mathrm{m})$ from Sample 1a are shown in Figure 9. It is interesting that these relatively large fragments are made from agglomerated fine Al particles despite no bonding between them was introduced during sample processing in CIPing. These fragments have different spacing between $\mathrm{W}$ particles and illustrate the effect of the local mesostructure on the plastic deformation of the $\mathrm{Al}$ particles between $\mathrm{W}$ particles. 

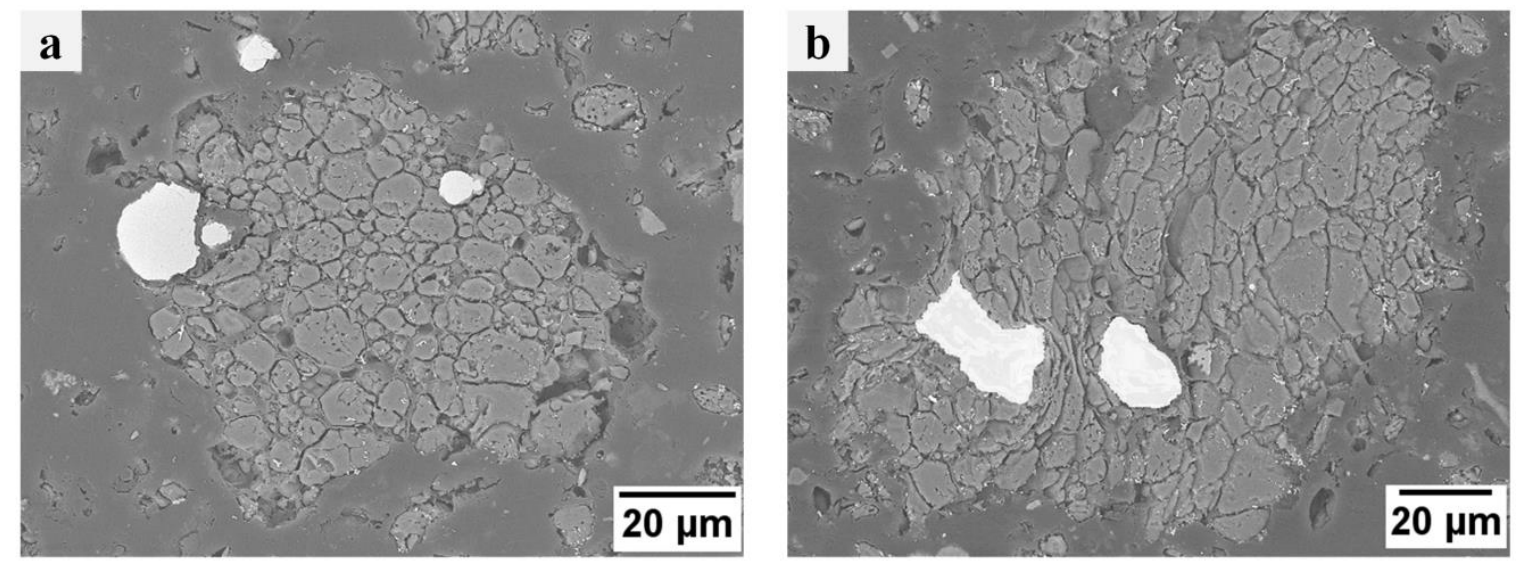

FIG. 9 Two polished and etched large size fragments $(\sim 100 \mu \mathrm{m}$ diameter $)$, representing agglomeration of fine $\mathrm{Al}$ particles, from the fine $\mathrm{Al}$ and $\mathrm{W}$ powder CIPed sample cold-mounted in epoxy (dark gray): (a) $\mathrm{Al}$ particles between $\mathrm{W}$ particles and in the outside area in the fragment have similar shape observed after CIPing. (b) Al particles are heavily deformed in the area between two relatively close $\mathrm{W}$ particles. Al particles are light grey and $\mathrm{W}$ particles are white.

$\mathrm{Al}$ particles between $\mathrm{W}$ particles separated by relatively large distance and in the outside area in the fragment presented in Figure 9(a) still have rounded shapes with a few having facets similar to the Al particles after CIPing (see Figure 3). This suggests that these particles experienced little or even no additional plastic deformation during fragmentation.

In contrast, $\mathrm{Al}$ particles located between two relatively close $\mathrm{W}$ particles are significantly elongated (Figure 9(b)) suggesting that these Al particles experienced large plastic deformation during the ring expansion and fragmentation process. Similar behavior of light small Al particles between large $\mathrm{W}$ particles in a PTFE matrix under shock loading was observed in numerical calculations $^{21}$. Such deformation of Al particles is not observed after CIPing alone (see Figure 3 ) indicating that this localized plastic flow of Al particles was specific for dynamic deformation and fragmentation.

In both cases $\mathrm{Al}$ particles on the boundaries of presented fragments do not show evidence of cleaving of these particles suggesting that fragmentation proceeded via opening of the interfaces between particles (CIPing does not result in bonding between Al particles). It reinforces that particle fragmentation is not the prevalent mode of fragmentation, in agreement with the observed distribution of particles (Figure 8(a)), where only small fraction is found to have a size smaller than the initial constituents.

Localized plastic flow of coarse and fine Al particles was also observed in samples with W fibers (CIPed and CIPed+HIPed) as shown in Figures 10 and 11, correspondingly. W fibers 
are removed from debris before the $\mathrm{Al}$ fragments are mounted in epoxy. Such deformation of $\mathrm{Al}$ particles is not observed after static compaction during samples preparation (see Figure 3) suggesting that this behavior of $\mathrm{Al}$ particles is also due to dynamic deformation and fragmentation.
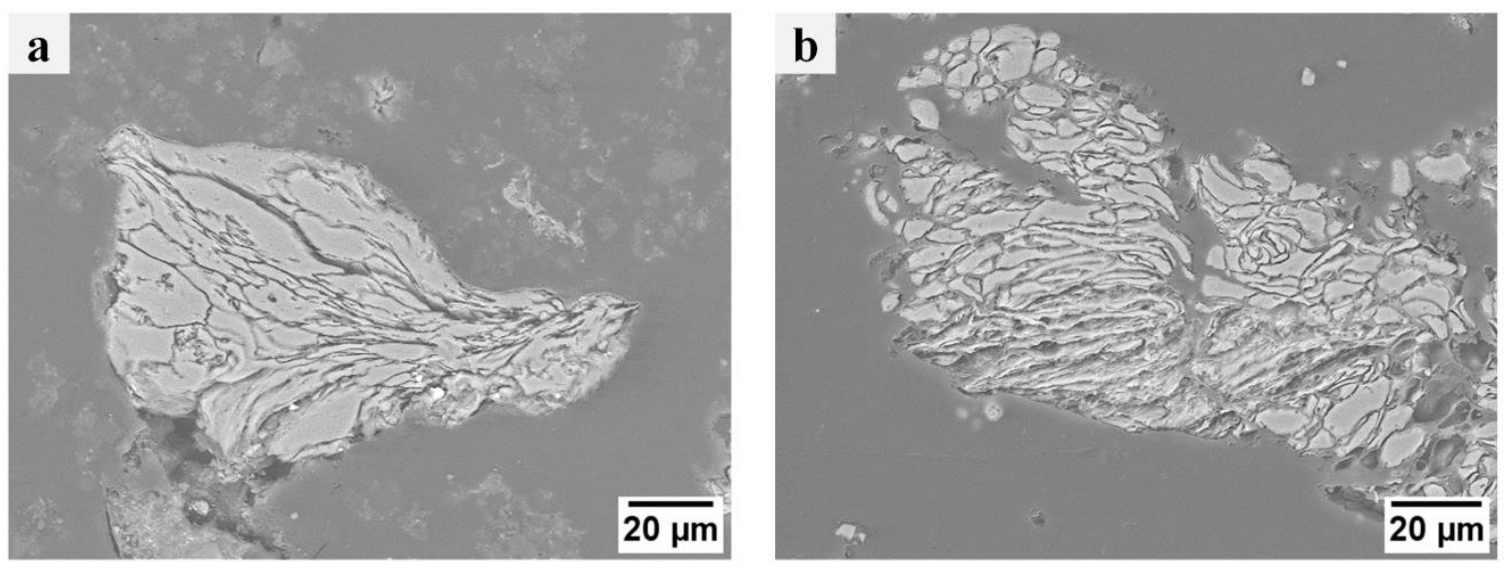

FIG. 10 SEM Images of the polished fragments from the coarse Al/W fibers samples cold-mounted in epoxy (dark gray) demonstrating high strain localized plastic flow of coarse $\mathrm{Al}$ particles presumably from the areas between W fibers: (a) fragment from CIPed only sample; (b) fragment from the CIPed+HIPed sample. Only $\mathrm{Al}$ particles (light grey) are present in these fragments.
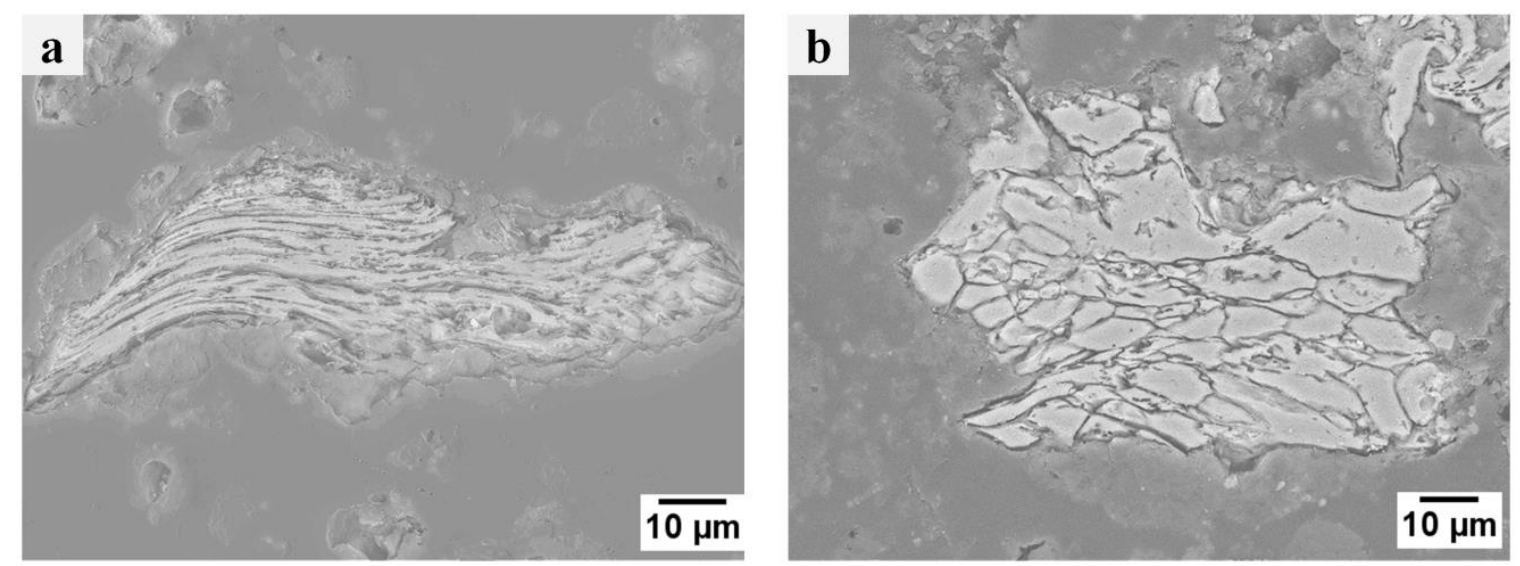

FIG. 11 SEM Images of the polished fragments from the fine Al/W fibers samples cold-mounted in epoxy (dark gray) demonstrating high strain localized plastic flow of fine $\mathrm{Al}$ particles presumably from the areas between W fibers: (a) fragment from CIPed only sample; (b) fragment from the CIPed+HIPed sample. Only Al particles (light grey) are present in these fragments.

It may also be possible that the submicron sized Al fragments (Figure 8(b) and 8 (c)) were generated in the high strain localized shear zones in CIPed+HIPed samples (Figures 10 and 11) where $\mathrm{W}$ fibers squeeze $\mathrm{Al}$ particles, elongating and breaking them. 
Recovered fragments from samples with different Al particles sizes and/or bonding conditions were very similar indicating that the fragmentation pattern is not sensitive to these variables.

The extrusion and plastic deformation of the light $\mathrm{Al}$ particles between heavy $\mathrm{W}$ particles or fibers may assist in the creation of fresh surfaces on the Al particles and improving their oxidation and subsequent combustion efficiency. The stored lattice defects caused by plastic flow and fragmentation can also increase particle reactivity.

\section{F. Microhardness of Al particles in fragments}

Some Al particles experienced significant plastic deformation during dynamic deformation and fragmentation (Figures 9-11). This process can result in the change of microhardness which can indicate whether Al particles were in situ annealed by the temperature increase caused by plastic flow.

Fragments after the explosive testing and samples before testing were cold-mounted in resin and then polished. Microhardness measurements were performed on the agglomerates of $\mathrm{Al}$ particles by a LECO Model M400-H1 hardness tester with a diamond shape indenter. A load of 10gf was applied to all fragments and specimens for 15 seconds. For comparison, microhardness of as-received fine $\mathrm{Al}(4.5-7 \mu \mathrm{m})$ particles, coarse $\mathrm{Al}$ (-325 mesh) particles and solid Al 6061-T6 (load force $=50 \mathrm{gf}$ instead of $10 \mathrm{gf})$ were also measured and equal to $196 \pm 9 \mathrm{MPa}, 213 \pm 11 \mathrm{MPa}$ and $1051 \pm 11 \mathrm{MPa}$, respectively. The results of the microhardness measurements are presented in Table IV.

TABLE IV. Microhardness of Al particles in processed Al/W samples with different mesostructure and in corresponding fragments.

\begin{tabular}{cccccc}
\hline \hline Hardness (MPa) & ${\text { Sample } 1 \mathrm{a}^{\mathrm{a}}}$ & ${\text { Sample } 2 \mathrm{a}^{\mathrm{b}}}$ & ${\text { Sample } 3 \mathrm{a}^{\mathrm{c}}}$ & Sample $^{\mathrm{d}}$ & Sample $^{\mathrm{e}}$ \\
\hline Processed samples & $503 \pm 10$ & $452 \pm 12$ & $304 \pm 11$ & $438 \pm 13$ & $289 \pm 12$ \\
Fragments & $475 \pm 23$ & $393 \pm 19$ & $368 \pm 20$ & $382 \pm 21$ & $356 \pm 19$ \\
\hline \hline
\end{tabular}

a fine Al/W powder, CIPed; ${ }^{b}$ coarse Al/W fibers, CIPed; ${ }^{c}$ coarse Al/W fibers, CIPed+HIPed; ${ }^{\text {ffine }} \mathrm{Al} / \mathrm{W}$

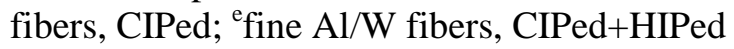

From the data in the Table IV, it is clear that CIPing and corresponding plastic deformation of fine $\mathrm{Al}$ particles caused by powder densification significantly increase their microhardness from $196 \pm 9 \mathrm{MPa}$ to $503 \pm 10 \mathrm{MPa}$ (in mixture with $\mathrm{W}$ particles) and to $438 \pm 13$ 
$\mathrm{MPa}$ (in mixture with $\mathrm{W}$ fibers). The microhardness of fine $\mathrm{Al}$ particles is based on measurements at distances away from $\mathrm{W}$ particles. The microhardness of $\mathrm{Al}$ particles in the immediate proximity to $\mathrm{W}$ particles has an even higher value $(542 \pm 8 \mathrm{MPa})$. The data demonstrates that CIPing of Al particles can significantly increase the density of crystal defects in Al, which is beneficial for the particle reactivity.

The smaller increase of microhardness of fine Al particles after CIPing in mixture with W fibers in comparison with $\mathrm{W}$ particles can be explained by higher strength of the interconnected W fibers network resulting in less plastic deformation of Al particles. After CIPing, the values of microhardness of coarse and fine Al particles in their mixtures with $\mathrm{W}$ fibers were similar. These values are still lower than microhardness of solid Al 6061-T6, which is equal to $1051 \mathrm{MPa}$.

For more clarity and easier comparison, the variation of microhardness in samples after processing and in fragments is illustrated in Figure 12. We can see that subsequent HIPing of the fine $\mathrm{Al} / \mathrm{W}$ fibers mixtures after CIPing resulted in decreased microhardness (from $438 \pm 13 \mathrm{MPa}$ to $289 \pm 12 \mathrm{MPa}$ ) due to annealing at elevated temperatures. HIPing of the coarse $\mathrm{Al} / \mathrm{W}$ fibers samples also demonstrated similar decreased microhardness (from $452 \pm 12 \mathrm{MPa}$ to $304 \pm 11$ $\mathrm{MPa}$ ). The microhardness of the fine and coarse $\mathrm{Al}$ particles in samples after $\mathrm{CIP}+\mathrm{HIP}$ processing was still higher than its initial values (289 MPa versus $196 \mathrm{MPa}$, and $304 \mathrm{MPa}$ versus $213 \mathrm{MPa}$, respectively). This indicates that HIPing introducing some bonding between $\mathrm{Al}$ particles preserved lattice defects accumulated mostly during plastic deformation in CIPing, which can be beneficial for the reactivity of Al fragments.
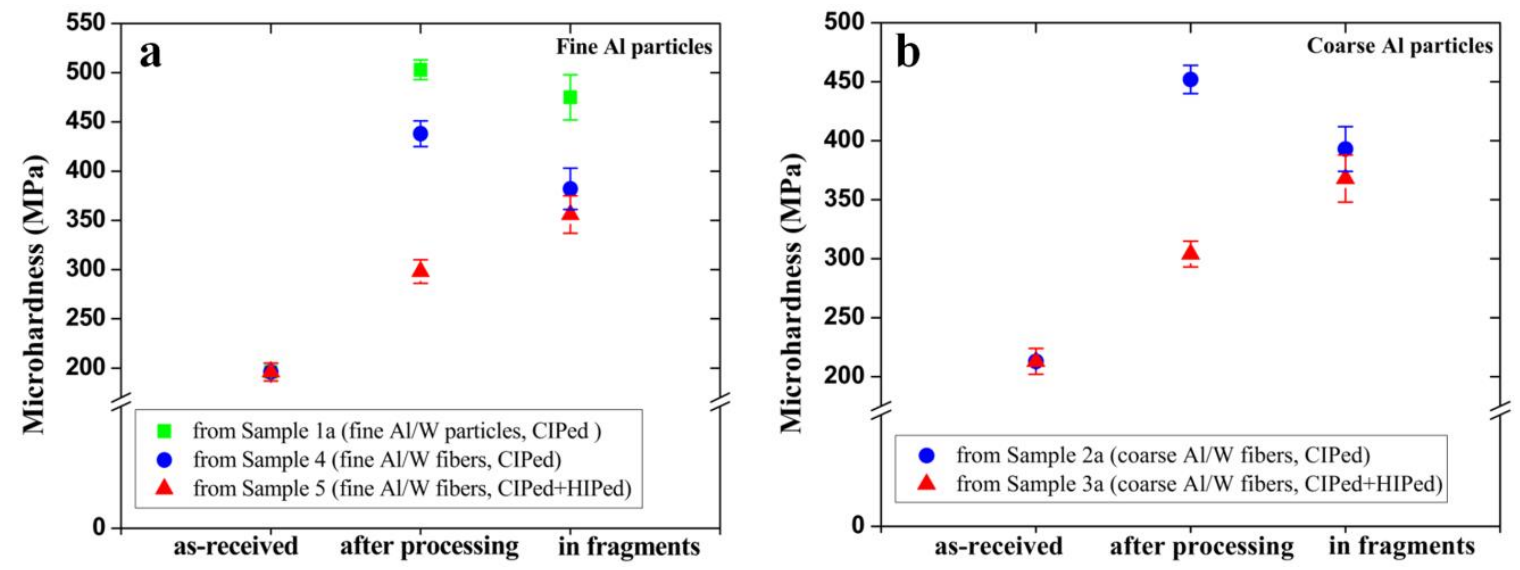

FIG. 12 Variations of Al particles microhardness in samples after different stages of processing and in fragments shown in horizontal axis for (a) fine $\mathrm{Al}$ and (b) coarse $\mathrm{Al}$. 
The microhardness of fine $\mathrm{Al}$ particles in fragments from CIPed fine $\mathrm{Al} / \mathrm{W}$ powder samples and from CIPed fine Al/W fibers samples was reduced from $503 \pm 10 \mathrm{MPa}$ to $475 \pm 23$ $\mathrm{MPa}$ and from $438 \pm 13 \mathrm{MPa}$ to $382 \pm 21 \mathrm{MPa}$, correspondingly (Figure 12). This change of microhardness can be explained by partial annealing due to heating caused by dynamic plastic deformation. Similar decrease of microhardness in fragments from CIPed coarse Al/W fibers samples was observed in the corresponding fragments (from $452 \pm 12 \mathrm{MPa}$ to $393 \pm 19 \mathrm{MPa}$ ).

The opposite behavior was observed in fragments from CIPed+HIPed coarse Al/W fibers and fine Al/W fibers samples in which microhardness in fragments increased from $304 \pm 11 \mathrm{MPa}$ to $368 \pm 20 \mathrm{MPa}$ and from $289 \pm 12 \mathrm{MPa}$ to $356 \pm 19 \mathrm{MPa}$, respectively. It is interesting that in fragments the microhardness of fine and coarse Al particles from CIPed+HIPed samples with W fibers was lower than their corresponding values after CIPing (Table IV, Figure 12). The qualitative difference of microhardness behavior in fragments from CIPed and CIPed+HIPed samples can be explained by the relatively low initial microhardness of CIPed+HIPed samples, which was increased due to plastic deformation in fragmentation process accompanied by less heating than plastic deformation of initially more porous CIPed samples.

The microhardness of Al particles in CIPed samples (about $500 \mathrm{MPa}$ in fine Al/W powder) is close to its saturated value which can be achieved by plastic deformation (e.g. in the ECAP process ${ }^{27}$ ). This suggests that additional plastic deformation during fragmentation process does not result in a significant increase of microhardness of $\mathrm{Al}$ in $\mathrm{CIPed} \mathrm{Al} / \mathrm{W}$ samples because Al particles were already significantly plastically deformed during densification process.

\section{NUMERICAL MODELING}

\section{A. Initial mesostructures}

Numerical simulations were performed with a finite element program, LS-Dyna, to elucidate the mechanisms of fragmentation during the explosively driven expansion of the granular composites and their dependence on sample mesostructure. Plane strain conditions were assumed in the calculations.

The volume fractions of the $\mathrm{Al}$ and $\mathrm{W}$ particles/fibers were kept similar to the experiment $(70 \% \mathrm{Al}$ and $30 \% \mathrm{~W})$. The mean size of all of the particles ( $\mathrm{Al}$ and $\mathrm{W}$ ) was assumed to be the same, $40 \mu \mathrm{m}$ diameter. The individual particles were created by using a Voronoi tessellation of 
the region. The mesh resolution for the $\mathrm{Al}$ and $\mathrm{W}$ particles was chosen such that $\sim 5$ elements spanned the diameter of the particle to adequately capture the stresses inside the particles. Since the experimental samples showed no bonding between the particles after the CIPing processing, the particles were allowed to slip and separate in the simulation.

There are two orders of magnitude difference in space scales between the mesostructure of the samples composed from $\mathrm{Al}$ and $\mathrm{W}$ particles/fibers (a few micrometers) and the global sizes of the ring samples (about $3 \mathrm{~cm}$ ). To accommodate this difference, a 10 degree wedge of the sample was simulated and the radial symmetry was assumed. In each case, a rigid wall boundary condition was used on the sides of the wedge.

For Al-W composites with $\mathrm{W}$ particles, the initial mesostructures used in simulations are presented in Figure 13 (Al particles in blue and W particles in red). Four different mesostructures were considered to clarify the influence of the porosity and pore size on the plastic strain accommodation and the material response during the fragmentation process.

The sample in Figure 13(a) has $1.2 \%$ initial porosity uniformly distributed along interfaces of particles due to small gaps formed when creating the mesh. This approach resulted in submicron pore sizes, much smaller than diameter of particles and the magnification in the insert of Figure 13(a) is not enough to make this porosity distribution visible. 

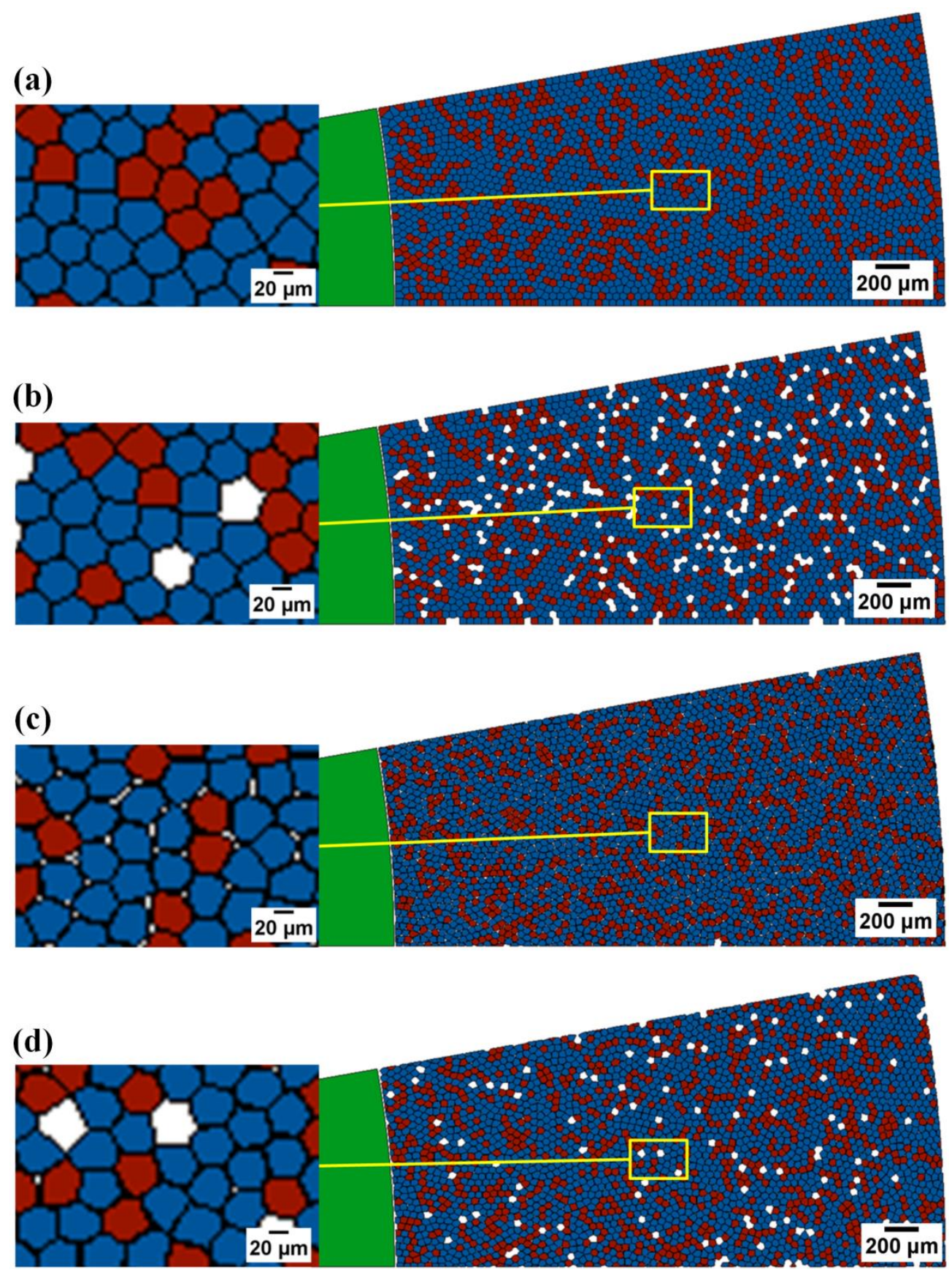

FIG. 13 Initial geometries of simulations representing the $\mathrm{Al}$ (blue) and $\mathrm{W}$ (red) powder cases. The $\mathrm{Al}$ and $\mathrm{W}$ powders were taken to be $40 \mu \mathrm{m}$ in diameter. The sample in (a) has $1.2 \%$ initial porosity with fine pores uniformly distributed along interfaces of particles and sizes much smaller than diameter of particles; mesostructure in (b) has the porosity $10 \%$ with larger pores having characteristic sizes equal one to few particle diameters; (c) mesostructure with a uniformly distributed porosity $10 \%$ and fine pores along particles interfaces; (d) mesostructure with $10 \%$ porosity and with two sizes of pores - fine pores uniformly distributed along particles interfaces similar to (c) and localized pores with sizes similar to particle sizes. The scales in the insets are different to make visible a difference in porosity distribution and sizes of pores. 
The samples in Figure 13(b)-(d) have $10 \%$ porosity created by different methods. In Figure 13(b) the porosity was created by removing $10 \%$ of the particles generating vacancy defects inside the sample. It resulted in much larger pores than in Figure 13(a) with characteristic sizes equal one to few particle diameters. In Figure 13(c), shrinking random edges of the particles resulted in a more uniformly distributed porosity along particle interfaces with a smaller characteristic pore size (about 4-8 $\mu \mathrm{m}$ ). The pores are easy to identify (compared to the sample with $1.2 \%$ porosity in Figure 13(a)) and are located around individual particles. Some of them are connected, forming small gaps along the interface of particles. Another approach using a combination of the methods mentioned above and is shown in Figure 13(d). Half of the porosity was created by the method used in Figure 13(b) and the other half of the porosity was created by the method used in Figure 13(c). In this mesostructure there are two sizes of pores, fine pores uniformly distributed along particles interfaces similar to Figure 13(c) and localized pores with sizes similar to one or few particle diameters.

Al-W composite with $\mathrm{W}$ fibers had significantly larger diameter of $\mathrm{W}$ inclusions (200 $\mu \mathrm{m})$ in comparison with $\mathrm{W}$ particles. Their initial geometries with different mesostructures $(0 \%$ and $10 \%$ initial porosities, correspondingly, with similar arrangements of $\mathrm{W}$ fibers) are presented in Figure 14. The Al particles (blue) and W fibers (red) were 40 and $200 \mu \mathrm{m}$ in diameters, respectively.
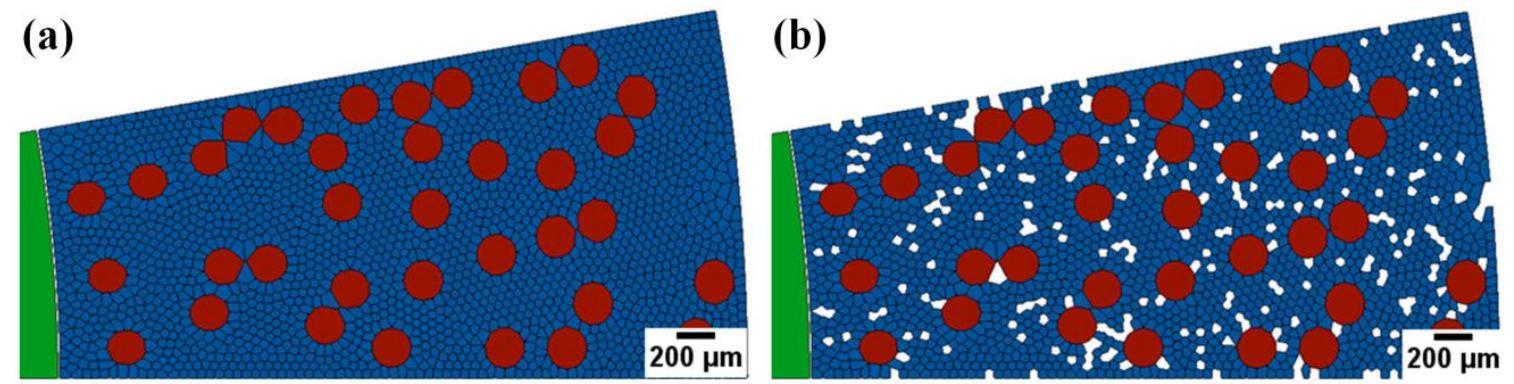

FIG. 14 Initial geometry for the Al (blue) powder and W (red) fiber samples with (a) no porosity and (b) $10 \%$ porosity.

All of the simulations with these initial mesostructures were driven using a compressed gas to represent the detonation products. 


\section{B. Materials modeling}

The dynamic behavior of $\mathrm{Al}, \mathrm{W}$ and $\mathrm{Cu}$ materials were modeled using a standard Johnson-Cook plasticity model ${ }^{28}$,

$$
\sigma_{y}=\left[A+B \bar{\varepsilon}_{p}^{n}\right]\left[1+C \ln \frac{\dot{\varepsilon}}{\dot{\varepsilon}_{0}}\right]\left[1-\left(\frac{T-T_{\text {room }}}{T_{\text {melt }}-T_{\text {room }}}\right)^{m}\right],
$$

where $A, B, C, n$, and $m$ are material parameters obtained from the open literature ${ }^{28-30}$ shown in Table V. The value of the initial yield stress, $A$, for the $\mathrm{Al}$ particles was adjusted to match $1 / 3$ of their microhardness values in the CIPed samples ${ }^{31}$.

TABLE V. Material parameters used in the Johnson-Cook constitutive model

\begin{tabular}{ccccccccc}
\hline & $\begin{array}{c}G \\
{\left[10^{-2} \mathrm{MBar}\right]}\end{array}$ & $\begin{array}{c}A \\
{\left[10^{-5} \mathrm{MBar}\right]}\end{array}$ & $\begin{array}{c}B \\
{\left[10^{-5} \mathrm{MBar}\right]}\end{array}$ & $n$ & $C$ & $m$ & $\begin{array}{c}\mathrm{C}_{\mathrm{p}} \\
{[\mathrm{J} / \mathrm{kg} \cdot \mathrm{K}]}\end{array}$ & $\begin{array}{c}T_{\text {melt }} \\
{[\mathrm{K}]}\end{array}$ \\
\hline $\mathrm{Al}$ & 26.0 & 174.0 & 114.0 & 0.42 & 0.002 & 1.34 & 885 & 932.0 \\
$\mathrm{~W}$ & 160.0 & 1506.0 & 176.5 & 0.12 & 0.016 & 1.0 & 134.5 & 1724.0 \\
$\mathrm{Cu}$ & 47.7 & 90.0 & 292.0 & 0.31 & 0.025 & 1.09 & 383 & 1356 \\
\hline \hline
\end{tabular}

To account for the possibility of particle fracture, a model based on the damage parameter $\mathcal{D}$ described in Ref. 28 was used

$$
\mathcal{D}=\sum \frac{\Delta \bar{\varepsilon}_{p}}{\varepsilon_{f}} .
$$

A material is considered failed when $\mathcal{D}=1$. The $\varepsilon_{f}$ is the equivalent strain at fracture, corresponding to the specific conditions of plastic deformation, and it can be computed using equation below

$$
\varepsilon_{f}=\left[D_{1}+D_{2} \exp D_{3} \frac{P}{\sigma_{e f f}}\right]\left[1+D_{4} \ln \frac{\dot{\varepsilon}}{\dot{\varepsilon}_{0}}\right]\left[1+D_{5} \frac{T-T_{\text {room }}}{T_{\text {melt }}-T_{\text {room }}}\right],
$$

where $\sigma_{e f f}$ is the effective stress and $D_{1}-D_{5}$ are the damage constants presented in Table VI. They were taken from the literature ${ }^{28-30}$.

TABLE VI. Damage constants used in the simulation.

\begin{tabular}{cccccc}
\hline \hline & $D_{1}$ & $D_{2}$ & $D_{3}$ & $D_{4}$ & $D_{5}$ \\
\hline $\mathrm{Al}$ & -0.77 & 1.45 & -0.47 & 0 & 1.6 \\
$\mathrm{~W}$ & 0 & 0.33 & -1.5 & 0 & 0 \\
$\mathrm{Cu}$ & 0.54 & 4.89 & -3.03 & 0.014 & 1.12 \\
\hline
\end{tabular}


The Johnson-Cook material model was used in conjunction with a Mie-Gruniesen equation of state where the pressure is defined as,

$$
\begin{array}{cc}
P=\frac{\rho_{0} C_{0}^{2} \mu\left[1+\left(1-\frac{\gamma_{0}}{2}\right) \mu-\frac{b}{2} \mu^{2}\right]}{\left[1-\left(S_{1}-1\right) \mu\right]^{2}}+\left(\gamma_{0}+b \mu\right) E & \text { if } \mu<0, \\
P=\rho_{0} C_{0}^{2} \mu+\left(\gamma_{0}+b \mu\right) E & \text { if } \mu>0,
\end{array}
$$

where $\mu=\rho / \rho_{0^{-}} 1$ and $C_{0}, \rho_{0}, b$, and $S_{1}$ are constants presented in Table VII taken from the literature $^{28}$.

TABLE VII. Material parameters used in the Mie-Gruneisen equation of state

\begin{tabular}{cccccc}
\hline \hline & $\rho_{0}[\mathrm{~g} / \mathrm{cc}]$ & $C_{\mathbf{0}}[\mathrm{cm} / \mu \mathrm{s}]$ & $S_{1}$ & $\gamma_{0}$ & $b$ \\
\hline $\mathrm{Al}$ & 2.70 & 0.524 & 1.4 & 1.97 & 0.48 \\
$\mathrm{~W}$ & 19.25 & 0.403 & 1.237 & 1.67 & 0.38 \\
$\mathrm{Cu}$ & 8.96 & 0.394 & 1.489 & 2.02 & 0.47 \\
\hline
\end{tabular}

To simulate the kinematics of explosively driven expansion, two different loading conditions were examined. In the first approach the interior of the $\mathrm{Cu}$ tube was moving with a velocity such that the average free surface velocity profile in the simulations matched that of the PDV records from the experiment.

The second was to model the detonation products as a pressurized gas with pressure given by

$$
P=\left(\gamma_{C J}-1\right) \frac{\rho}{\rho_{C J}} E
$$

where the initial parameters of the detonation products were determined using the ChapmanJouget relations ${ }^{32,33}$ :

$$
\begin{aligned}
& \rho_{C J}=\rho_{0} \frac{\gamma_{C J}+1}{\gamma_{C J}}, \\
& P_{C J}=\rho_{0} \frac{D^{2}}{\gamma_{C J}+1},
\end{aligned}
$$

where $P_{C J}, \gamma_{C J}, \rho_{C J}, D$ are the pressure, Gruneisen parameter, density, and detonation speed at the Chapman-Jouget point. The initial pressure $P_{C J}$ was scaled by reducing the energy term to account for the free space within the experimental assembly such that the final free surface velocity profiles in the simulations were in agreement with the experimental data for corresponding samples. The following explosive parameters were used in the numerical 
calculations ${ }^{18}$ : initial density $\rho_{0}=1.46 \mathrm{~g} / \mathrm{cm}^{3}$, detonation speed $D=6800 \mathrm{~m} / \mathrm{s}$, and polytropic exponent for detonation products $\gamma_{C J}=3$.

\section{Kinematics of samples expansion}

Granular Al-W composites have a complex mesostructure which can influence the kinematics of expansion. To verify the approach of explosive driver, numerical calculations of the expansion of the solid stainless steel rings, which are significantly less heterogeneous than our granular composites, were first performed. The free surface velocities of stainless steel rings in the simulation and in the experiments are shown in Figure 15.

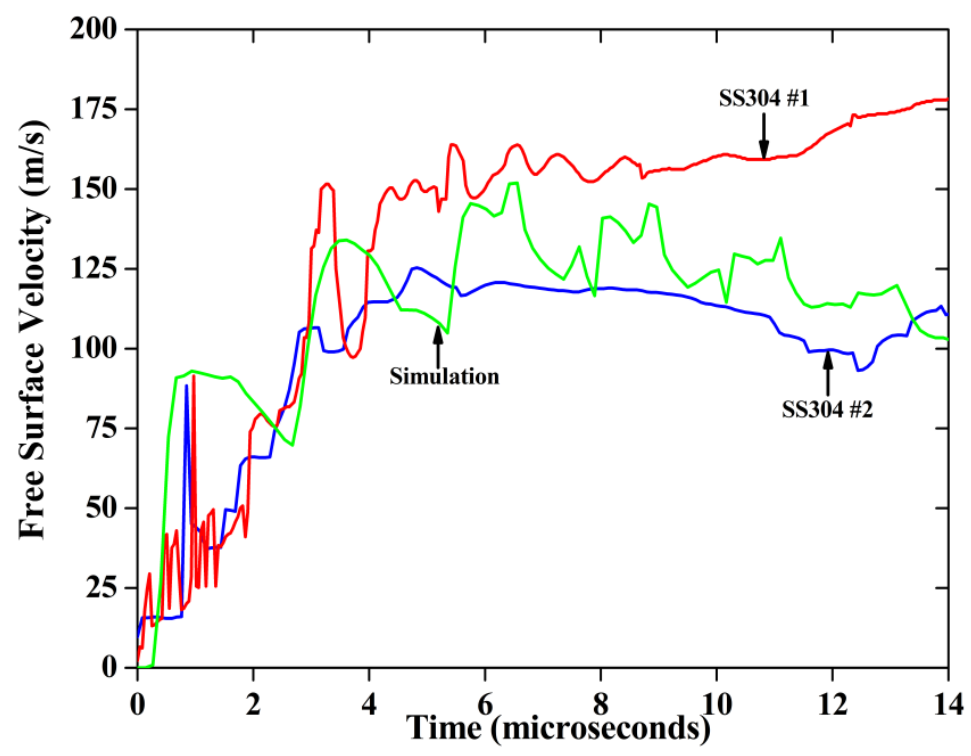

FIG. 15 The comparison of free surface velocity profiles of stainless steel ring samples in experiments and simulations with the pressurized gas model for detonation products.

Comparison of numerical results and experimental data for stainless steel rings demonstrate a reasonable agreement, thus validating the approach used to model explosive driver.

Numerical simulations of time-resolved velocities of the outside surface of the Al-W granular composite samples, corresponding to mesostructures presented in Figure 13 and 14, are shown in Figure 16. For comparison, experimental results related to three granular Al/W Samples 1 (porosity 10\%) are also shown. The expansion of the samples in simulations was driven by the pressurized gas explosive model presented above. 


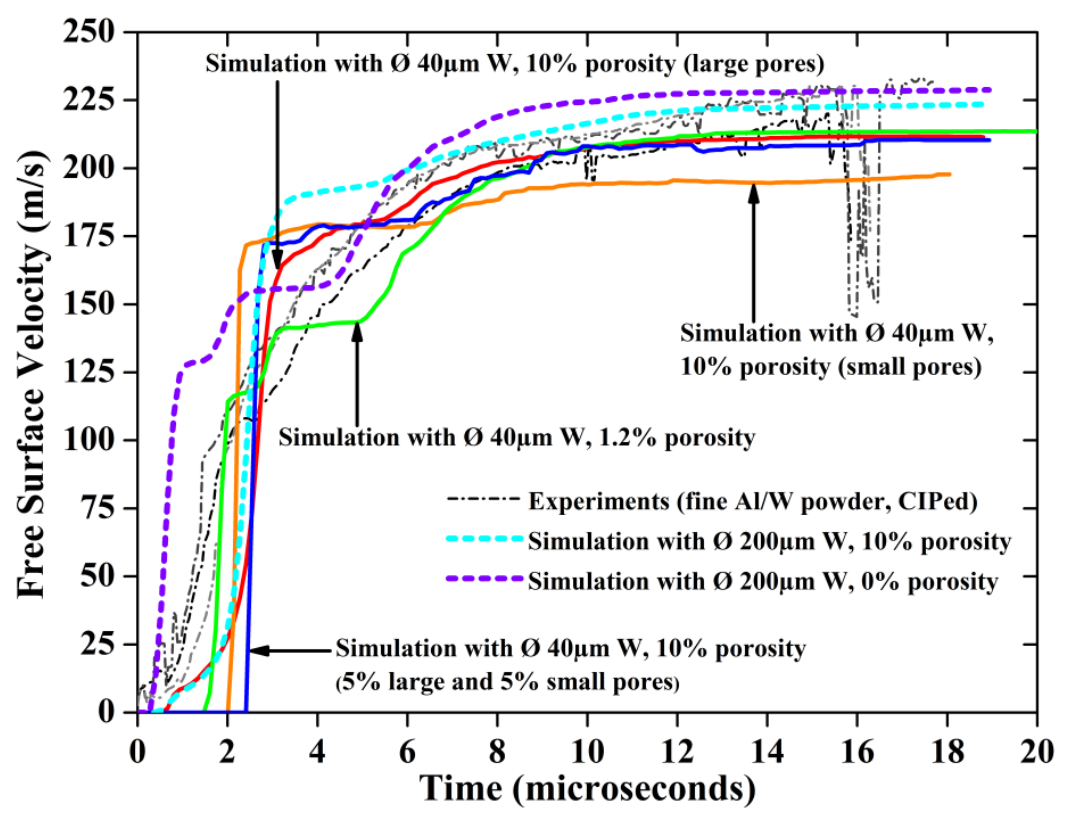

FIG. 16 Free surface velocity in the simulations for the $\mathrm{Al}$ and $\mathrm{W}$ powders small rings with different porosity and pore sizes corresponding to mesostructures presented in Figures 13 and 14. The three curves related to experimental results for granular Al/W Samples 1 (Table II) are also shown.

From Figure 16 it is clear that gradual increase of the particle velocity profile in experiments is reproduced in numerical calculations for samples with $10 \%$ porosity and with large sizes of pores (at least $40 \mu \mathrm{m}$ ) comparable to the diameter of $\mathrm{Al}$ particles, and for samples with porosity $10 \%$ and containing large $\mathrm{W}$ inclusions with diameter $200 \mu \mathrm{m}$ (corresponding to $\mathrm{W}$ fibers). A corresponding initial mesostructures are shown in Figure 13(b) and 14(b).

On the contrary, a strong initial jump in the free surface velocity was evident in the numerical results for rings with four different initial mesostructures: (1) samples with a very small porosity uniformly distributed along interfaces of particles with corresponding voids having sizes much smaller than diameter of particles (1.2\% porosity, Figure 13(a)); (2) samples with small pores (4-8 $\mu \mathrm{m}$ in diameter and 10\% porosity, Figure 13(c)); and (3) samples with mixed large and small pores (10\% porosity, Figure 13(d)) and (4) samples containing large W inclusions with diameter $200 \mu \mathrm{m}$ and $0 \%$ porosity (Figure 14(a)). Sizes of W inclusion did not affect the velocity profiles for samples with similar porosities (Figure 16).

The final expansion velocity of the samples was satisfactorily modeled in numerical calculations for all samples. Clear shock reverberations were present only in samples with porosity $1.2 \%$. The simulations related to samples with small pores (about $4-8 \mu \mathrm{m}$ ) and $10 \%$ porosity demonstrated slightly less expansion velocity $(\sim 190 \mathrm{~m} / \mathrm{s})$ compared to other samples 
$(\sim 210 \mathrm{~m} / \mathrm{s})$. The differences in the initial ramping time may not be very important for the fragmentation process because it happens at a later time when the rings have accumulated large strains, reaching almost constant expansion velocity.

\section{Fragmentation patterns of samples with small $W$ inclusions}

The fragmentation patterns of samples with small $\mathrm{W}$ inclusions (40 $\mu \mathrm{m}$ diameter) after 20 microseconds $(\mu \mathrm{s})$ from the start of the simulation (where expansion velocity reached a maximum) are presented in Figure 17. The estimated area of all simulated Al-W samples has increased after $20 \mu \mathrm{s}$. This indicates additional porosity was introduced due to shear deformation. The sample with initial 10\% porosity and large sizes of pores (Figure 13(b)) increase least (about $10 \%$ ) and other three types of samples (with $1.2 \%$ porosity, Figure $13(\mathrm{a})$; with $10 \%$ porosity and small sizes of pores, Figure 13(c); and with $10 \%$ porosity and mixed large and small pores, Figure 13(d)) increase about 20\%. With larger pores, it may be easier to redistribute initial porosity through the volume thus lower volume increase.

Comparing initial mesostructures and ones after $20 \mu$ s from the start of the simulation, we observed densified areas with closed pores between the shear zones. For example, in Figure 17 (d), there are large dense areas in triangle and rectangular shapes at the top where the corresponding initial mesostructure has pores. 


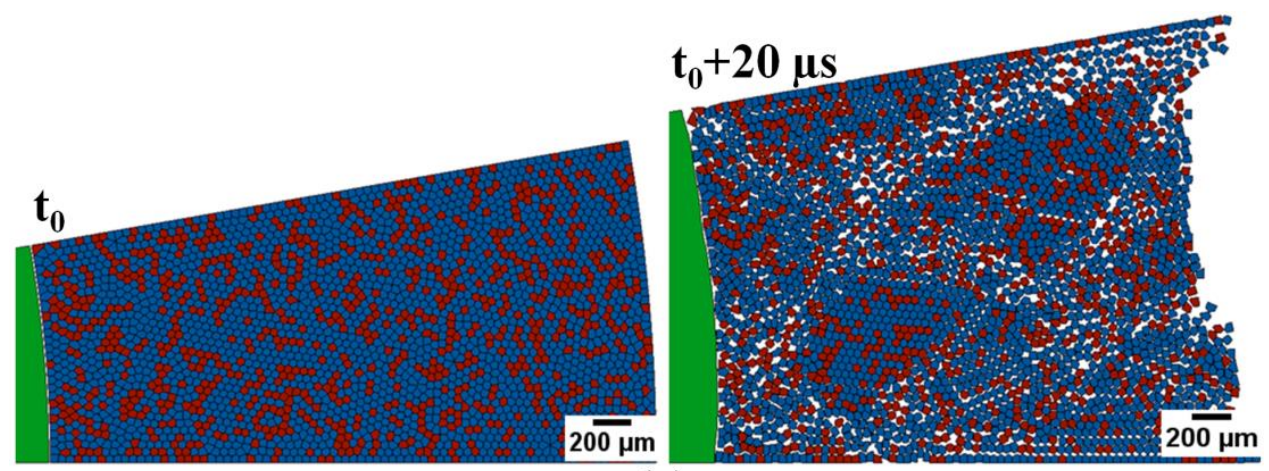

(a)

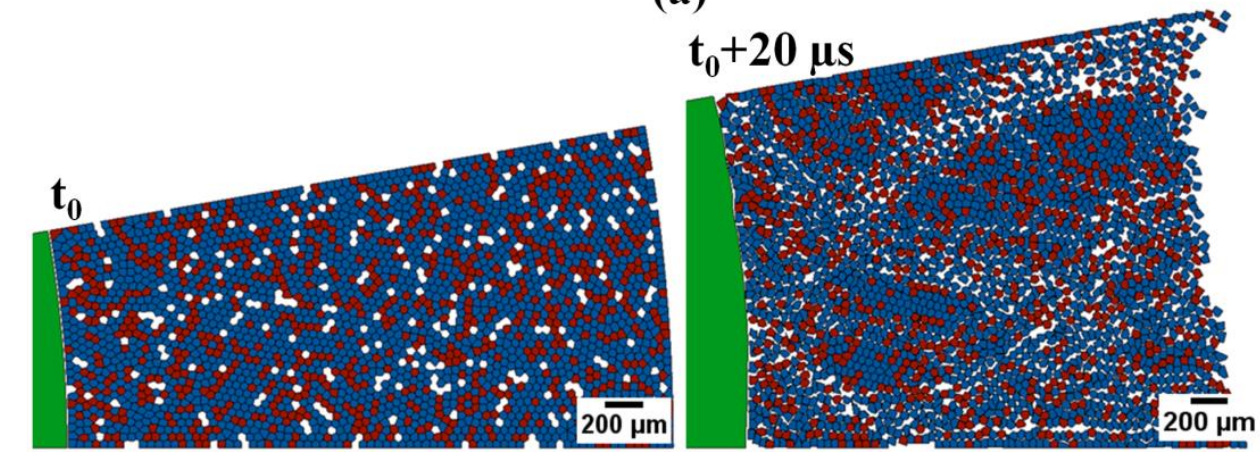

(b)

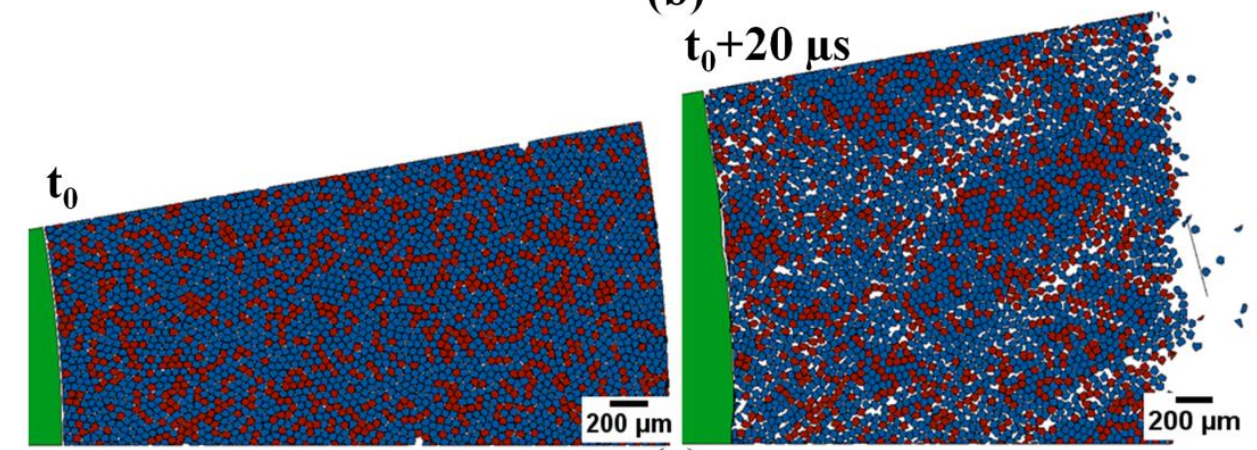

(c)

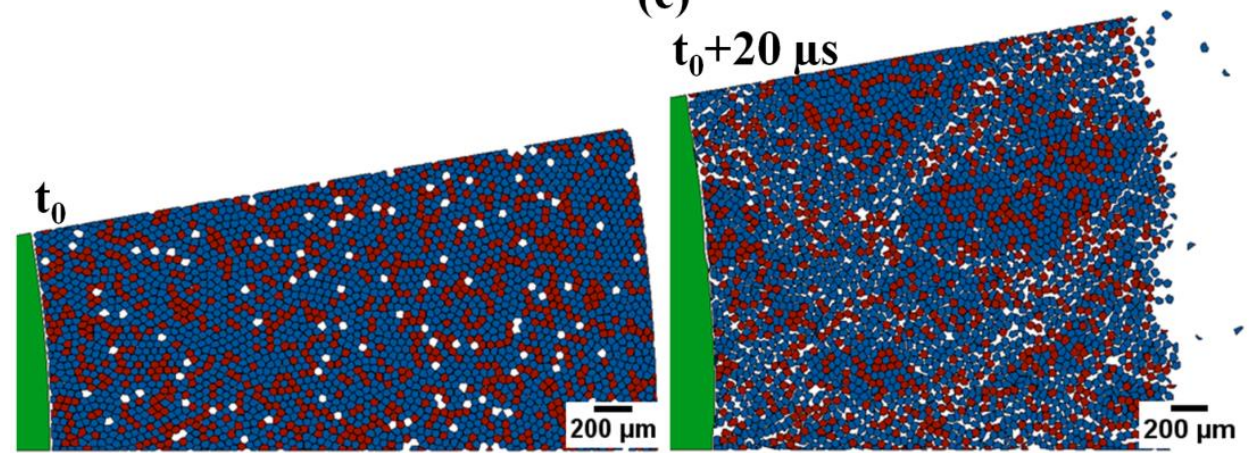

(d)

FIG. 17 The mesostructure of the simulated $\mathrm{Al}$ and $\mathrm{W}$ powders small rings after $20 \mu$ s from the start of the simulation. The sample in (a) has $1.2 \%$ initial porosity and the samples in (b)-(d) have $10 \%$ initial porosity generated by different methods. Al particles are blue and $\mathrm{W}$ particles are red. 
It seems that in all samples the shear zones were initiate at about $+45^{\circ}$ from the radius and this is unaffected by the initial mesostructures: porosity, pore sizes and pore distribution. For the simulation with small pores (about 4-8 $\mu \mathrm{m}$ ) and 10\% porosity (Figure 17(c)), the shear zone at $-45^{\circ}$ is much less developed compared to other 3 cases. This may be due to the collapsing of small pores and densification of particles thus blocking the shear instability. This may also explain the slightly lower expansion velocity observed in Figure 16. Larger pores are collapsed relatively slowly and they may coalesce into forming shear zones with increased porosity instead of collapsing. Regions between the sheared zones are possible areas where larger size fragments are formed and where materials are densified due to plastic deformation of particles. This suggests that the particles between shear zones are shielded from mesoscale pulverization. At the same time, significant movements of individual particles are observed within the shear band zone, potentially leading to fracture.

The distribution of effective plastic strain in simulations corresponding to $\mathrm{Al}$ and $\mathrm{W}$ powders is presented in Figure 18. Areas that are colored dark blue have no plastic strain, while areas in red have an effective plastic strain greater than 0.3 . The simulations with $10 \%$ initial porosity have significantly more plastic strain than the simulation with $1.2 \%$ porosity. Furthermore, in the sample with the large pores (Figure 18(b)), the effective plastic strain was more localized to the regions around the initial pores, and significant elongation of some $\mathrm{Al}$ particles in this region was observed, similar to observed in experiments (Figure 9). From a reactive material standpoint, this result suggests that larger pore sizes are more desirable as they promote large plastic strains in the $\mathrm{Al}$ which may be beneficial for ignition/reaction. No separation of particles during the expansion process was observed in numerical simulations despite the fact that the particles are not bonded. 
(a)

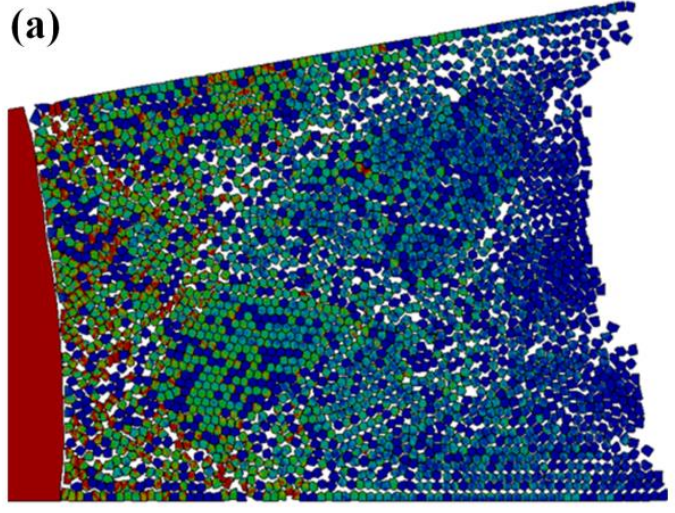

(c)

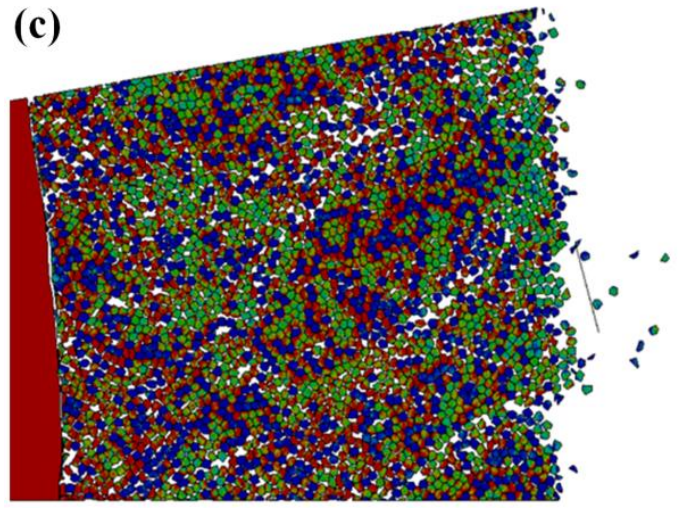

(b)

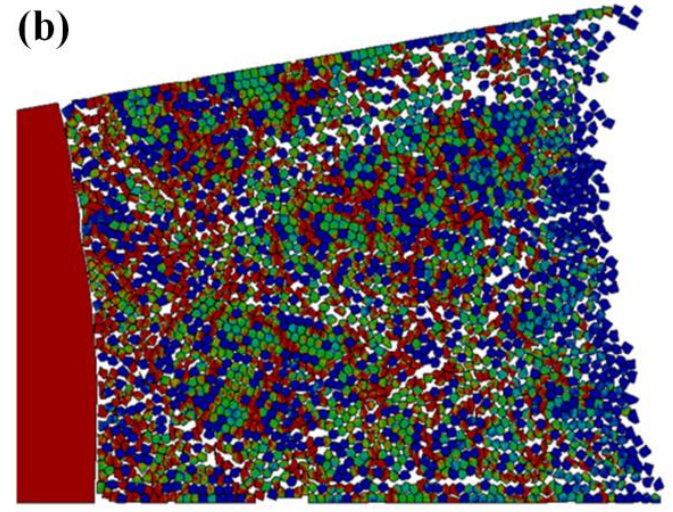

(d)

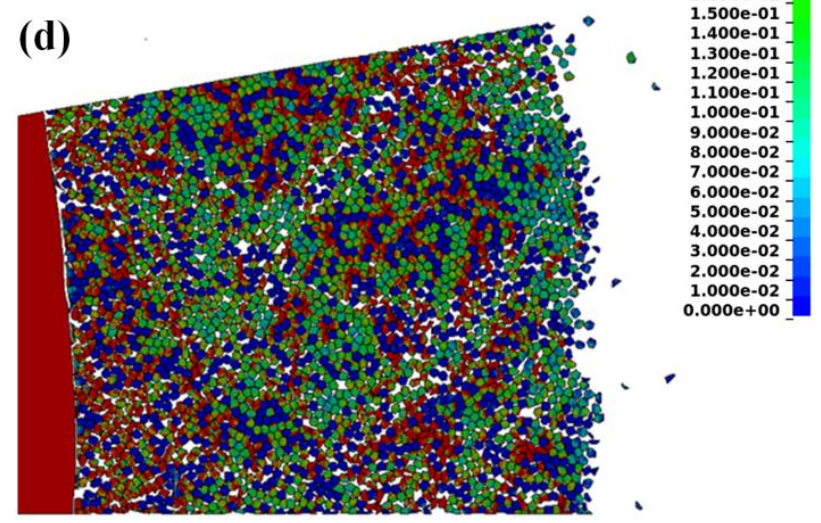

FIG. 18. The distribution of effective plastic strain in $\mathrm{Al}$ and $\mathrm{W}$ powder simulations. Areas that are colored dark blue have no plastic strain, while areas in red have an effective plastic strain greater the 0.3. The sample in (a) has $1.2 \%$ initial porosity and the samples in (b)-(d) have $10 \%$ porosity generated by different methods.

It is clear from Figure 18 that the added porosity increases the effective plastic strain in some Al particles, e.g., see densified areas with large strains in Al particles in Figure 18(b)-(d). This increase can be attributed to the large strain plastic flow of Al particles into the pores during compression by the initial shock wave. The plastically deformed Al particles accumulated damage and therefore softening (Eqs. 4 and 5). But this localized softening which occurred throughout the bulk sample did not act as a global softening mechanism resulting in bands of lower density at 45 degrees to radius. Localization of strains in these global shear bands was probably due to the dilation mechanism of softening. Densified areas between these bands could be responsible for the generation of the larger fragments $(100-300 \mu \mathrm{m})$ in the experiment. Also, it is clear that the larger plastic strains occur in the interior region of the samples such that these regions are more likely to generate larger fragments in comparison to the outer regions where most of particles show little plastic deformation. 
Higher strains in $\mathrm{Al} / \mathrm{W}$ samples occurred near the interface with $\mathrm{Cu}$ driver corresponding to the shock wave entrance and between or close to $\mathrm{W}$ particles. In simulation with $10 \%$ porosity, outer $\mathrm{Al}$ particles have higher strains and when small pores (about 4-8 $\mu \mathrm{m}$ ) are present in the initial mesostructures.

\section{E. Fragmentation patterns of samples with large $W$ inclusions}

The fragmentation patterns of samples with large $\mathrm{W}$ inclusions $(200 \mu \mathrm{m}$ diameter, corresponding to $\mathrm{W}$ fibers) at $20 \mu \mathrm{s}$ after the start of expansion process is presented in Figure 19. The simulated samples have 0\% (Figure 19(a)) and 10\% (Figure 19(b)) initial porosity. In both cases, samples show similar global fragmentation features that are likely dictated by the initial geometrical arrangement of $\mathrm{W}$ fibers. Both samples also show some clustering of $\mathrm{Al}$ particles between the shear band zones. Thus pattern of shear band zones can form multi-particle fragments with larger sizes than the initial particle which were also observed in experiments (Figures 10 and 11).

Expansion in circumferential direction is evident based on the relative positions of $\mathrm{W}$ fibers (Figure 19) which results in increased porosity in both samples. It is interesting that this increase of porosity with expansion depends on initial mesostructure. The initially more porous sample increases its volume by $9 \%$ and initially solid sample by $19 \%$. 


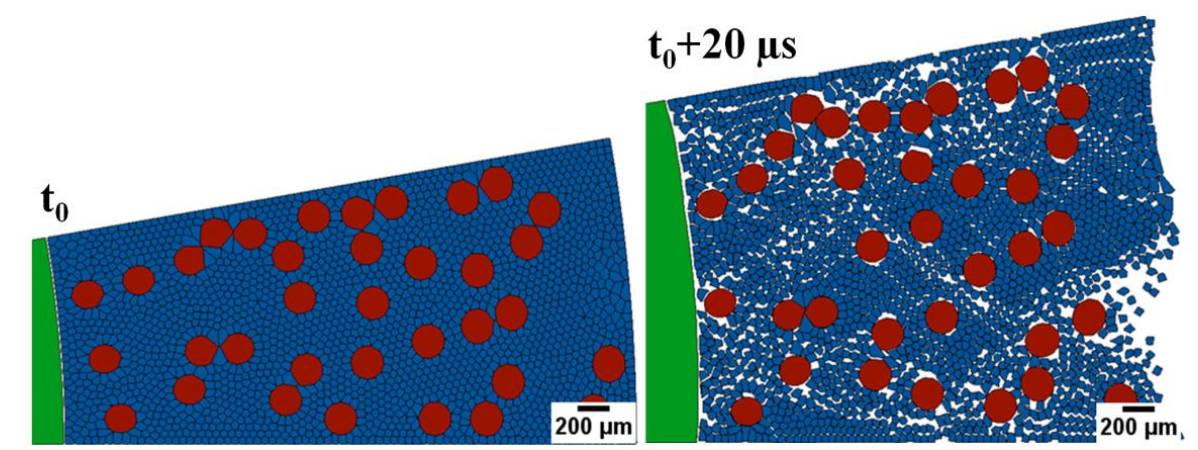

(a)

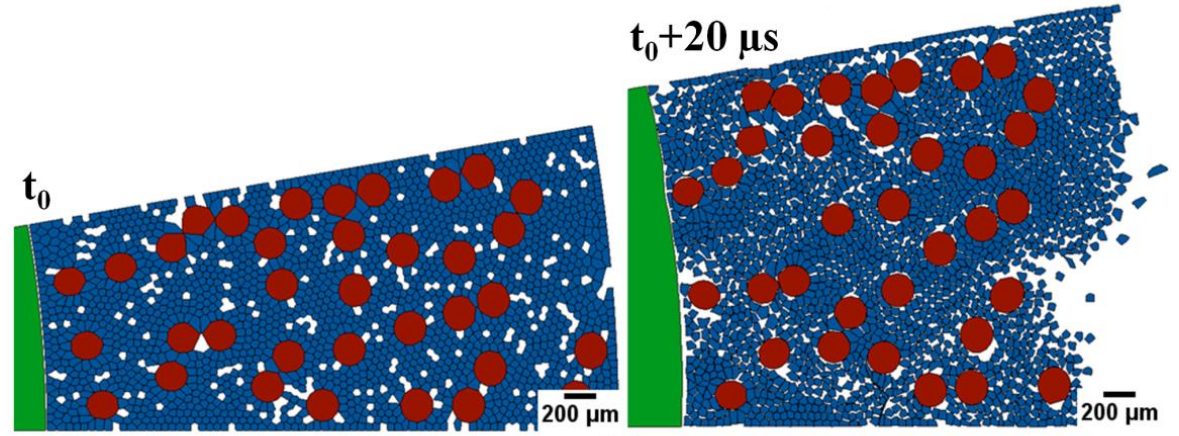

(b)

FIG. 19 The mesostructure of the simulated sample corresponding to the CIPed samples with Al powder and $\mathrm{W}$ fibers at $20 \mu \mathrm{s}$ after the detonation. The simulated samples have (a) no porosity and (b) $10 \%$ porosity. Al particles are blue $\mathrm{W}$ fibers are red.

The distribution of effective plastic strain in the fibers simulations is presented in Figure 20. The sample with $10 \%$ initial porosity (Figure 20(b)) exhibits significantly more plastic strain, localized in clusters of Al particles, than in the simulation without initial porosity (Figure 20(a)).
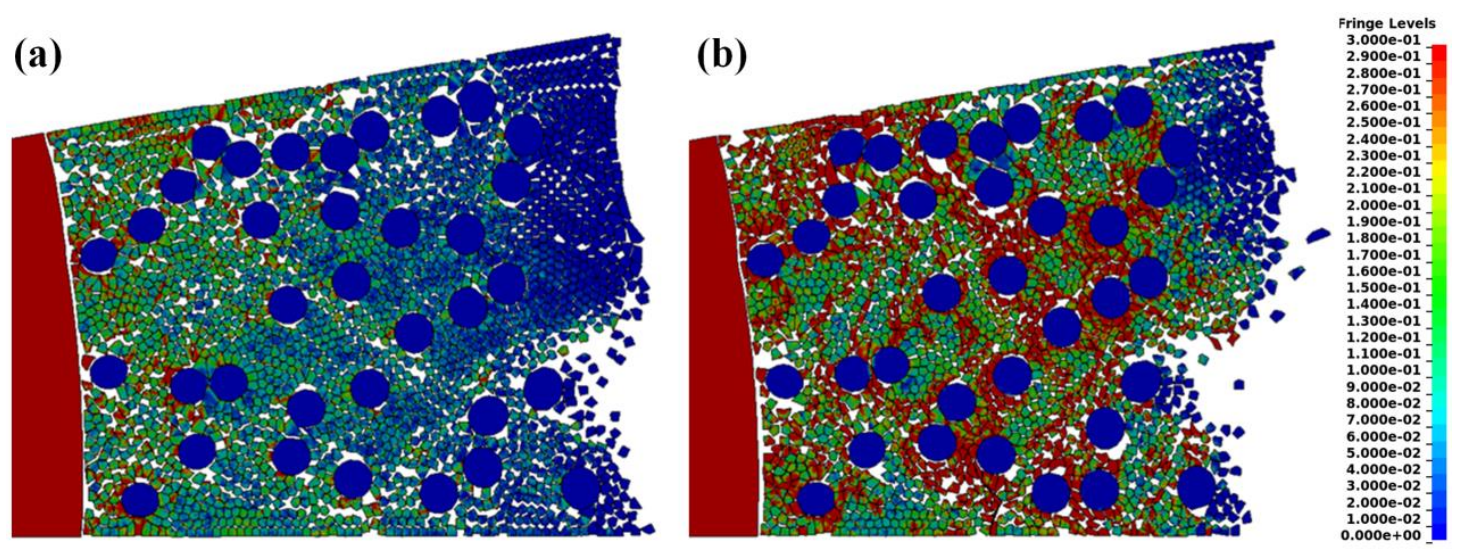

FIG. 20 The effective plastic strain for the simulations with initial mesostructures presented in Figure 14. The simulated samples initially have (a) no porosity and (b) $10 \%$ porosity. 
Additionally, higher values of effective plastic strain were observed in Al neighboring the $\mathrm{W}$ fibers for both cases. This may explain the observed behavior of Al particles in recovered debris (Figure 10). A significant difference between Al-W samples with $\mathrm{W}$ particles and W fibers is that in the latter case there is effect of interlocking $\mathrm{W}$ fibers which is not modeled in these calculations. The strength of this network may contribute to the enhanced pulverization of Al matrix.

\section{CONCLUSIONS}

Al-W particulate composite rings with different mesostructures (particulate $\mathrm{Al}$ and $\mathrm{W}$, particulate $\mathrm{Al}$ and $\mathrm{W}$ fibers) and bonding between $\mathrm{Al}$ particles were processed using CIPing and CIPing+HIPing. Their fragmentation mechanisms were investigated through explosively driven dynamic expansion. The kinematics of this process was monitored using PDV measurements of the outside surface velocity. PDV records of expanding heterogeneous, particulate rings demonstrated no change in behavior between samples with partially bonded and unbonded Al particles.

An experimental setup was developed to allow for soft recovery of a significant part of the debris. XRPD of the debris demonstrated that the Al and $\mathrm{W}$ did not react despite their high strain, high strain rate mutual plastic flow.

Distributions of debris sizes showed that the Al-W rings were pulverized mostly back to particulate state (the mean fragment sizes in the range of $10-20 \mu \mathrm{m}$ ).

Particle size analysis demonstrated that debris have a noticeable number of particles with sizes below the range of the original particle sizes. We consider that these fine particulates were created due to localization of deformation on two structural levels - between neighboring $\mathrm{W}$ inclusions and inside shear bands propagating through the thickness of the rings. The former mechanism was active during initial shock wave loading and subsequent high strain rate expansion of rings where $\mathrm{Al}$ particles were squeezed and fractured between neighboring $\mathrm{W}$ inclusions. The latter was active during high strain, high strain rate expansion of rings. 
The agglomerated fragments larger than sizes of initial Al particles were also observed in experiments. The characteristic size of these agglomerates is most likely determined by the spacing between $\mathrm{W}$ inclusions.

The explosive fragmentation of $\mathrm{Al} / \mathrm{W}$ rings in this paper was investigated under the same conditions as fragmentation of rings made from densified $\mathrm{Al}$ powder reported previously ${ }^{14}$. More than an order of magnitude difference exists in the sizes of fragments between these two sample types, demonstrating the dramatic influence of mesostructure on fragmentation mechanisms related to the presence of $\mathrm{W}$ inclusions in our samples.

Numerical simulations of the expansion velocity of rings were in agreement with the experimental PDV data. The simulations show that dynamically expanded rings had clusters of particulates between shear bands. These shear bands develop into macrocracks and the particle clusters expand without significant plastic deformation. It is likely that this is the mechanism which generates larger fragments of agglomerated $\mathrm{Al}$ and $\mathrm{W}$ particles even when they are not bonded. It is probable that $\mathrm{Al}$ particles are fragmented during the expansion process inside the shear band regions where localized high strain plastic flow was observed in numerical calculations. Simulations agree with experiments in that Al particles between neighboring W particles/fibers are more heavily plastically deformed in comparison with Al particles away from W inclusions. Simulations show that an increase in the initial porosity of the compacted particulate rings (about 10\%) increases the plastic straining of $\mathrm{Al}$ particles between $\mathrm{W}$ particles/fibers. Thus initial porosity may be beneficial for promoting temperature increase of $\mathrm{Al}$ and cracking of surface oxide layers on $\mathrm{Al}$ particles, therefore increasing their subsequent oxidation in air.

\section{Acknowledgements}

The support of this project was provided by the Office of Naval research Multidisciplinary University Research Initiative Award N00014-07-1-0740, Program Manager Dr. Clifford D. Bedford.

\section{References:}

${ }^{1}$ N. N. Thadhani, Journal of Applied Physics 76, 2129 (1994). 
2 I. Sraj, P. E. Specht, N. N. Thadhani, T. P. Weihs, and O. M. Knio, Journal of Applied Physics 115, 023515 (2014).

${ }^{3}$ M. D. Grapes, T. LaGrange, K. Woll, B. W. Reed, G. H. Campbell, D. A. Lavan, and T. P. Weihs, APL Materials 2 (2014).

${ }^{4}$ M. W. Beckstead, Combustion Explosion and Shock Waves 41, 533 (2005).

5 N. N. Thadhani, Progress in Materials Science 37, 117 (1993).

${ }^{6}$ V. F. Nesterenko, Dynamics of Heterogeneous Materials, $1^{\text {st }}$ ed. (Springer, New York, 2001).

7 R. G. Ames, Materials Research Society Symposium Proceedings 896, 10 (2006).

8 J. P. Hooper, Journal of Applied Physics 112 (2012).

${ }^{9}$ M. E. Kipp and D. E. Grady, Journal of the Mechanics and Physics of Solids 33, 399 (1985).

${ }^{10}$ D. Frost and F. Zhang, in Proc. 19th Military Aspects of Blast and Shock (Calgary, Canada, 2006).

${ }^{11}$ F. Zhang, H. Grönig, and A. Van de Ven, Shock Waves 11, 53 (2001).

${ }^{12}$ F. Zhang, K. B. Gerrard, R. C. Ripley, and V. Tanguay, in Shock Waves: 26th International Symposium on Shock Waves, Volume 1, edited by K. Hannemann and F. Seiler (Springer Berlin Heidelberg, Berlin, Heidelberg, 2009), p. 395.

${ }^{13}$ V. Tanguay, S. Goroshin, A. J. Higgins, and F. Zhang, Combustion Science and Technology 181, 670 (2009).

${ }^{14}$ A. M. Marquez, C. H. Braithwaite, T. P. Weihs, N. M. Krywopusk, D. J. Gibbins, K. S. Vecchio, and M. A. Meyers, Journal of Applied Physics 119, 145903 (2016).

${ }^{15}$ P.-H. Chiu and V. F. Nesterenko, DYMAT, EPD Sciences 2, 947 (2009).

${ }^{16}$ K. L. Olney, P.-H. Chiu, C. W. Lee, V. F. Nesterenko, and D. J. Benson, Journal of Applied Physics 110, 114908 (2011).

${ }^{17}$ P.-H. Chiu, C. W. Lee, and V. F. Nesterenko, AIP Conference Proceedings 1426, 737 (2012).

${ }^{18}$ V. F. Nesterenko, P.-H. Chiu, C. H. Braithwaite, A. Collins, D. M. Williamson, K. L. Olney, D. Benson, and F. McKenzie, AIP Conference Proceedings 1426, 533 (2012).

${ }^{19}$ P.-H. Chiu, K. L. Olney, C. Braithwaite, A. Jardine, A. Collins, D. J. Benson, and V. F. Nesterenko, Journal of Physics Conference Series 500, 112017 (2014).

${ }^{20}$ V. E. Panin, V. Nesterenko, S. Kul'kov, and A. Mel'nikov, Fizika Goreniya i Vzryva 27, 140 (1991).

${ }^{21}$ E. B. Herbold, V. F. Nesterenko, D. J. Benson, J. Cai, K. S. Vecchio, F. Jiang, J. W. Addiss, S. M. Walley, and W. G. Proud, Journal of Applied Physics 104, 103903 (2008).

${ }^{22}$ V. F. Nesterenko, M. A. Meyers, H. C. Chen, and J. C. Lasalvia, Metallurgical and Materials Transactions A: Physical Metallurgy and Materials Science 26, 2511 (1995).

${ }^{23}$ H. C. Chen, J. C. Lasalvia, V. F. Nesterenko, and M. A. Meyers, Acta Materialia 46, 3033 (1998).

${ }^{24}$ F. A. Burgmann, D. G. McCulloch, L. Ryves, S. H. N. Lim, D. R. McKenzie, and M. M. M. Bilek, Journal of Physics: Condensed Matter 21, 055003 (2009).

${ }^{25}$ T. H. Van Steenkiste, J. R. Smith, and R. E. Teets, Surface \& Coatings Technology 154, 237 (2002).

${ }^{26}$ R. C. Ripley, L. Donahue, and F. Zhang, Shock Waves 25, 151 (2015).

${ }^{27}$ M. I. Abd El Aal and M. M. Sadawy, Transactions of Nonferrous Metals Society of China 25, 3865 (2015).

${ }^{28}$ G. R. Johnson and W. H. Cook, Engineering Fracture Mechanics 21, 31 (1985).

${ }^{29}$ T. J. Holmquist, D. W. Templeton, and K. D. Bishnoi, International Journal of Impact Engineering 25, 211 (2001). 
${ }^{30}$ D. Steinberg, Equation of state and strength properties of selected materials (Lawrence Livermore National Laboratory Livermore, CA, 1996).

${ }^{31}$ M. F. Ashby and D. R. H. Jones, Engineering Materials (Pergamon Press, Oxford, 1980).

${ }^{32}$ D. L. Chapman, The London, Edinburgh, and Dublin Philosophical Magazine and Journal of Science 47, 90 (1899).

${ }^{33}$ Y. B. Zeldovich, J. Exptl. Theoret. Phys. (U.S.S.R.) 10, 542 (1940). 